\title{
Avaliação da influência da técnica de execução no comportamento de revestimento de argamassa aplicado com projeção mecânica contínua
}

\author{
Evaluation of the influence of the execution technique on \\ cement-based render applied by continuous mechanical \\ projection
}

\author{
Kátia Cristina Zanelatto \\ Mércia Maria Semensato Bottura de Barros \\ Renata Monte \\ Fernando Henrique Sabbatini
}

\section{Resumo}

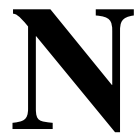

o Brasil, a execução dos revestimentos de argamassa com projeção mecânica contínua tem crescido nos últimos anos. Embora a utilização desse sistema tenha potencial de contribuir para a melhoria da qualidade dos revestimentos de argamassa, os diferentes procedimentos adotados durante sua produção não foram avaliados sistemicamente. O objetivo deste trabalho é avaliar experimentalmente a influência de algumas variáveis - umidade do substrato; umidade da argamassa; número e espessura das demãos; intervalo entre demãos; técnica de aplicação da argamassa, e técnica de acabamento superficial - no comportamento dos revestimentos executados por projeção mecânica contínua da argamassa, particularmente no que

Kátia Cristina Zanelatto Departamento de Engenharia de Construção Civil, Escola Politécnica Universidade de São Paulo Avenida Professor Almeida Prado,

Trav. 2, n. 83, Butantã São Paulo - SP - Brasil CEP 05508-900 Tel.: (11) 99124-2166

E-mail: katia.zanelatto@usp.br

Mércia Maria Semensato Bottura de Barros Departamento de Engenharia de Construção Civil, Escola Politécnica Universidade de São Paulo Tel.: (11) 3091-5790

E-mail: mercia.barros@poli.usp.br

Renata Monte

Departamento de Engenharia de Construção Civil, Escola Politécnica Universidade de São Paulo Tel. (11) 3091-5384

E-mail: renata.monte@poli.usp.br

Fernando Henrique Sabbatini Departamento de Engenharia de Construção Civil, Escola Politécnica Universidade de São Paulo Tel.: (11) 3091-5793 E-mail:

fernando.sabbatini@poli.usp.br

Recebido em 24/06/10/12 Aceito em 12/03/13 se refere a sua adesão inicial e fissuração e aderência do revestimento. Os resultados obtidos indicaram que a utilização da projeção mecânica contínua da argamassa proporciona um acréscimo significativo da resistência de aderência à tração, em comparação à aplicação manual, e que a técnica de acabamento denominada raspagem pode prejudicar significativamente o comportamento desses revestimentos. Além disso, a condição de umidade do substrato, o teor de umidade da argamassa e o tempo entre demãos são variáveis que interagem fortemente, podendo influenciar positiva ou negativamente o comportamento dos revestimentos.

Palavras-chave: Revestimento de argamassa. Argamassa projetada. Desempenho dos revestimentos. Resistência de aderência à tração. Adesão inicial. Fissuração.

\section{Abstract}

In Brazil, the execution of cement-based render by using the wet spraying method using rotor-type machines has grown in recent years. Despite the potential of this system to contribute to improve the quality of rendering, the different execution procedures employed during its production still have not been systematically evaluated. The aim of this paper is to evaluate the influence of a set of variables - the moisture condition of the substrate; moisture content of the mortar; thickness and number of coats; time interval between coats; and application technique of the mortar; and surface finishing technique - on the rendering behavior, more specifically on initial bonding, cracking and adhesion, through experimental evaluation. The results led to the conclusion that the mechanical projection of mortar promotes a significant increase in adhesion when compared to manual application and that the surface finish technique called scraping can significantly impair the behavior of these renderings. Furthermore, the substrate moisture condition, the mortar moisture content, and the time between coats are variables that strongly interact and positively or negatively influence the behavior of these coatings.

Keywords: External cement based render. Mortar spraying. Rendering behavior. Adhesion strength. Initial bond. Cracking. 


\section{Introdução}

Enquanto em muitos países europeus a produção de revestimento tem sido feita utilizando-se a projeção mecânica contínua de argamassas (AUSTIN; ROBINS; GOODIER, 2002), no Brasil, mesmo havendo um potencial para sua difusão, impulsionado pela necessidade premente de industrialização, poucas construtoras a utilizam (CICHINELLI, 2010a).

$\mathrm{Na}$ maior parte do país a aplicação da argamassa ocorre por lançamento manual (Figura 1) e, em algumas empresas, em que se buscou a racionalização do processo de produção, é utilizada a projeção mecânica por spray a ar comprimido (Figura 2) (CRESCÊNCIO et al., 2000; ANTUNES; JOHN, 2007), equipamento que possibilita o uso de argamassas produzidas em canteiros de obras, uma técnica largamente difundida no país.

A projeção mecânica contínua (Figura 3), por sua vez, exige argamassas com reologia tal que sejam possíveis seu bombeamento e projeção contínuos (SANTOS, 2003), o que não tem sido possível obter com aquelas argamassas, principalmente em função de variações nas propriedades dos materiais constituintes.

Figura 1 - Lançamento manual
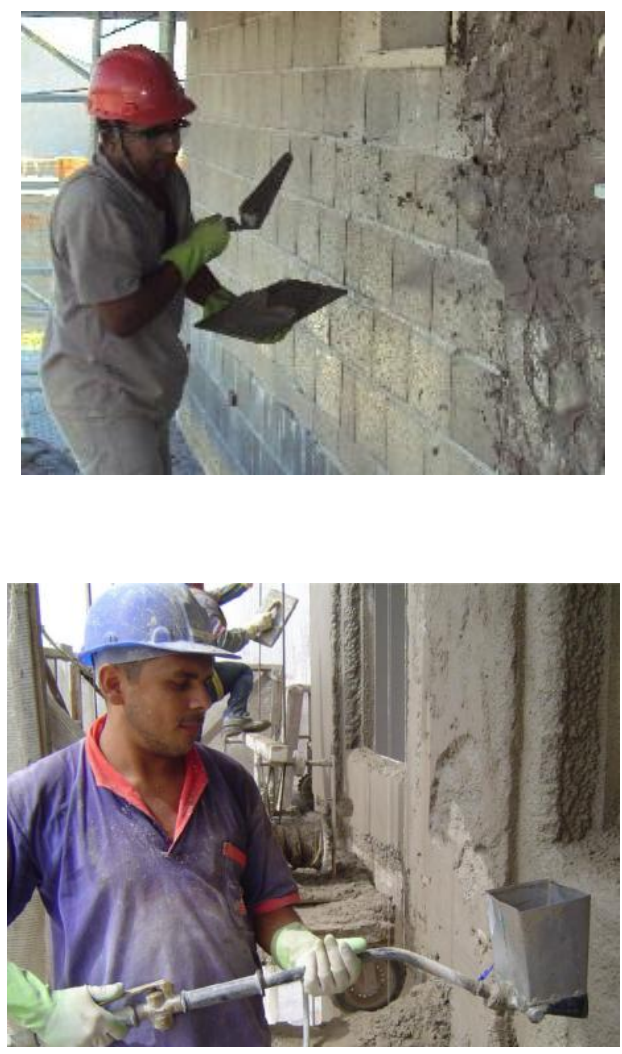

Figura 2 - Projeção por spray a ar comprimido

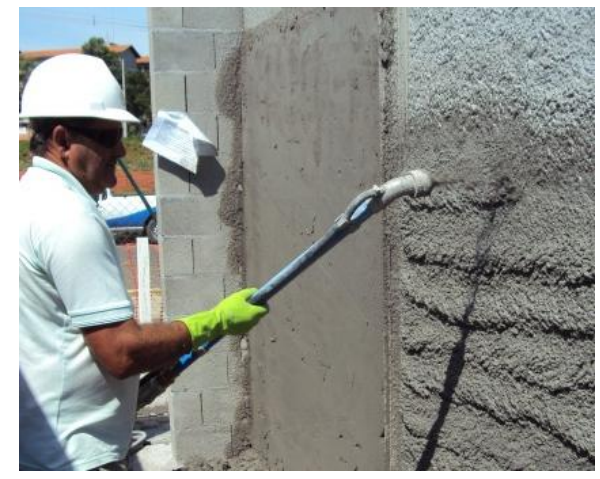

Figura 3 - Projeção mecânica contínua

88 Zanelatto, K. C,; Barros, M. M. S. B. de; Monte, R.; Sabbatini, F. H. 
Argamassas industrializadas têm sido desenvolvidas especificamente para esse uso, e suas propriedades reológicas, em princípio, permitem promover alterações na técnica tradicional de execução do revestimento, visando facilitar sua execução. Por exemplo, a tradicional etapa de compressão da camada de argamassa com o dorso da colher de pedreiro (Figura 4) vem sendo substituída pelo alisamento ou espalhamento com a régua "H" (CRESCÊNCIO et al., 2000;
SANTOS, 2003) (Figura 5), enquanto o tradicional sarrafeamento, feito com régua retangular (Figura 6), vem sendo substituído pela raspagem com régua $\mathrm{H}$ (Figura 7 ). Essas técnicas são distintas principalmente em relação à ferramenta utilizada $\mathrm{e}$ à umidade da camada no momento da execução. A raspagem somente é executada com reduzida umidade da camada (quase seca), que é muito menor do que a umidade durante o sarrafeamento.

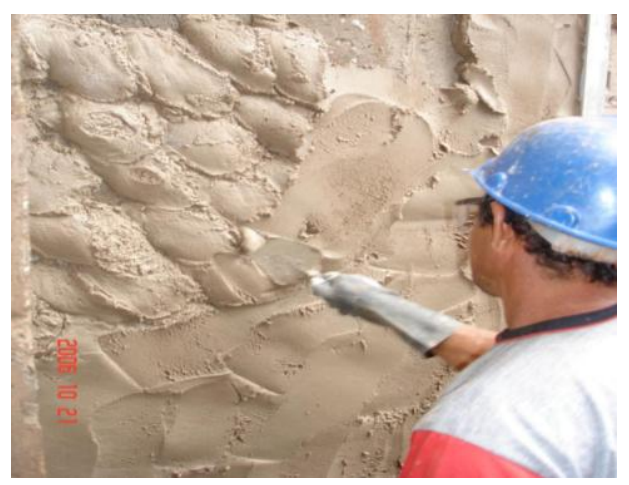

Figura 4 - Compressão da argamassa com o dorso da colher de pedreiro após lançamento manual

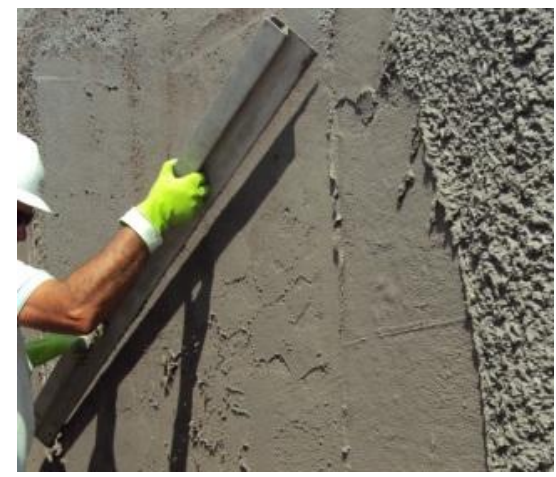

Figura 5 - Alisamento com régua H após projeção mecânica contínua da argamassa

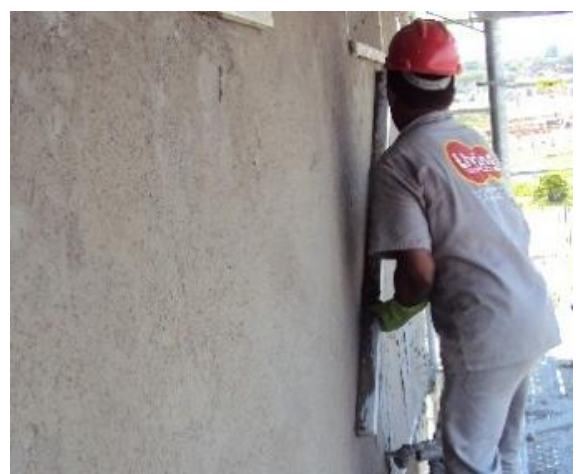

Figura 6 - Sarrafeamento tradicional: corte do excesso de argamassa com régua retangular 


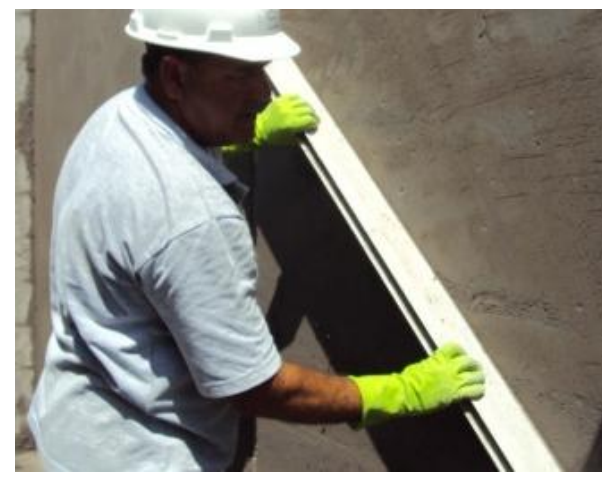

Figura 7 - Raspagem com régua $\mathrm{H}$ : remoção do excesso de argamassa por raspagem da superfície

As técnicas de aplicação dos revestimentos de argamassa - compressão da camada com a colher ou alisamento com régua - buscam promover maior contato da argamassa com a superfície do substrato (SANTOS, 2003) e, inclusive, com suas reentrâncias, o que potencializa a aderência dos revestimentos. As técnicas de acabamento sarrafeamento e raspagem -, por sua vez, também podem influenciar na aderência do revestimento ao substrato, assim como em seu grau de fissuração (SABBATINI, 1990)

A própria técnica de projeção contínua da argamassa influencia o comportamento dos revestimentos (CRESCÊNCIO et al., 2000; MAIDL, 1995). Resultados de estudos indicam que, com a aplicação mecânica das argamassas, é possível potencializar a adesão inicial e, com isso, obter valores de resistência de aderência em torno de $50 \%$ superiores aos obtidos com a aplicação manual. Além disso, a variabilidade dos resultados diminui, sobretudo devido à menor interferência do fator humano (ANTUNES; JOHN, 2007; DUIABILE; CAVANI; OLIVEIRA, 2005; FERNANDES et al.; 2007).

A facilidade ou dificuldade com que se realizam as atividades de execução dos revestimentos com projeção mecânica contínua dependem de fatores relacionados a algumas condições que podem variar no canteiro de obra, tais como a condição de umidade do substrato, o teor de água da argamassa, o intervalo entre demãos e a condição de umidade da argamassa no momento do sarrafeamento e do desempeno.

No entanto, não foram encontrados trabalhos que tenham avaliado sistemicamente a influência dessas variáveis no comportamento do revestimento produzido por projeção mecânica contínua da argamassa. O objetivo deste trabalho é, pois, avaliar experimentalmente a influência das principais variáveis da técnica de execução no comportamento dos revestimentos executados por projeção mecânica contínua da argamassa, particularmente no que se refere a sua adesão inicial, fissuração e aderência do revestimento.

\section{Materiais e métodos}

O trabalho experimental como um todo foi desenvolvido em quatro etapas: levantamento de campo para a definição das variáveis de estudo; e duas etapas experimentais propriamente ditas laboratório e campo. Estas etapas experimentais foram precedidas de uma etapa intermediária de preparação.

\section{Etapa 1: levantamento de campo}

Esta etapa envolveu visita a cinco canteiros de obras que utilizavam a técnica de aplicação em estudo, visando caracterizar suas etapas de execução e identificar suas principais variáveis.

Os resultados desse levantamento, apresentados em Zanelatto (2012), possibilitaram definir as principais variáveis:

(a) condição de umidade do substrato: seco ou umedecido $24 \mathrm{~h}$ antes;

(b) teor de umidade da argamassa: 22\%, 25\%, $28 \%$;

(c) espessura e número de demãos: $2 \mathrm{~cm}$ (uma demão); 0,3 cm + 1,7 cm (duas demãos); ou $1 \mathrm{~cm}$ $+1 \mathrm{~cm}$ (duas demãos);

(d) intervalo entre demãos: úmido sobre úmido (30, 60 ou $90 \mathrm{~min}$ ) ou úmido sobre seco (24 h);

(e) tempo para acabamento superficial: 10, 20, 40, 60 ou 120 min; e

(f) técnica de acabamento superficial: raspagem ou sarrafeamento tradicional.

Para complementar o estudo, a técnica de projeção mecânica foi comparada à aplicação da argamassa por lançamento manual e com desempenadeira. 


\section{Etapa 2: preparação para avaliação experimental}

Para ambas as etapas - laboratório e campo foram constituídos substratos de alvenaria de blocos de concreto, cujas características e respectivos métodos de ensaio são apresentados na Tabela 1.

O bloco de concreto foi selecionado como substrato por suas condições superficiais propícias à ancoragem da argamassa sem necessidade de aplicação de chapisco (BAUER; PAES, 2004; CANDIA; FRANCO, 1998; CARASEK, 1996; SCARTEZINI et al., 2002). Assim, eliminou-se uma atividade de produção do revestimento também passível de variações.

Sobre esses substratos foram produzidos vinte e sete painéis de revestimento, sendo $15 \mathrm{em}$ laboratório, identificados pelo número do painel seguido da letra L (Figura 8) e 12 em campo, designados pelo número do painel seguido da letra C (Figura 9).

O mercado de materiais disponibiliza diversas argamassas para projeção mecânica contínua (CICHINELLI, 2010b). Entre elas, foi selecionada uma que fosse adequada ao substrato de alvenaria de bloco de concreto sem chapisco, cujas características são apresentadas na Tabela 2.

Entre os diversos equipamentos de mistura e projeção disponíveis no mercado, foi utilizado o equipamento MAI@4JOB BUSINESS (Figura 10), com bomba de projeção helicoidal Mai Rotor D72,5 + Mai Stator D7-2,5, com vazão nominal de saída de $32 \mathrm{~L} / \mathrm{min}$. Nesse equipamento, a argamassa, previamente misturada à água, é depositada sobre a entrada da bomba helicoidal, sendo bombeada e transportada pela mangueira até a pistola e, então, projetada sobre o substrato.

Tabela 1 - Caracterização do bloco de concreto

\begin{tabular}{|c|c|c|c|}
\hline Característica avaliada & Método de ensaio & Idade & Resultados médios \\
\hline Resistência à compressão & NBR 12118 (ABNT, 2011) & \multirow{3}{*}{+ de 28 dias } & $4,5 \mathrm{MPa}$ \\
\hline Absorção de água total & NBR 12118 (ABNT, 2011) & & $6,14 \%$ \\
\hline $\begin{array}{l}\text { Índice de absorção inicial } \\
\text { na face de revestimento }\end{array}$ & $\begin{array}{c}\text { ASTM C } 67 \\
\text { (AMERICAN..., 2012) }\end{array}$ & & $75 \mathrm{~g} / \mathrm{cm}^{2}$ \\
\hline
\end{tabular}

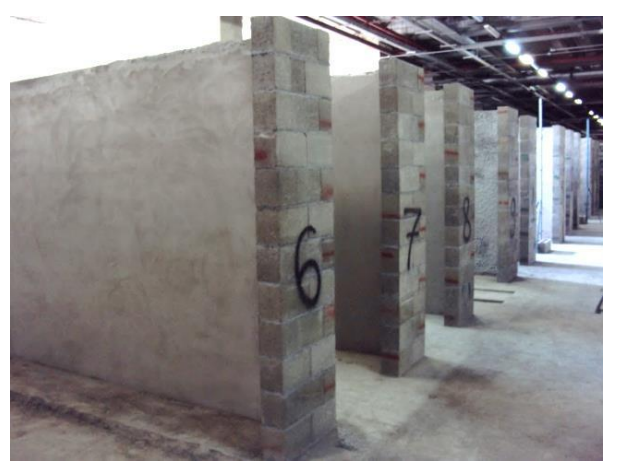

Figura 8 - Painéis executados em laboratório

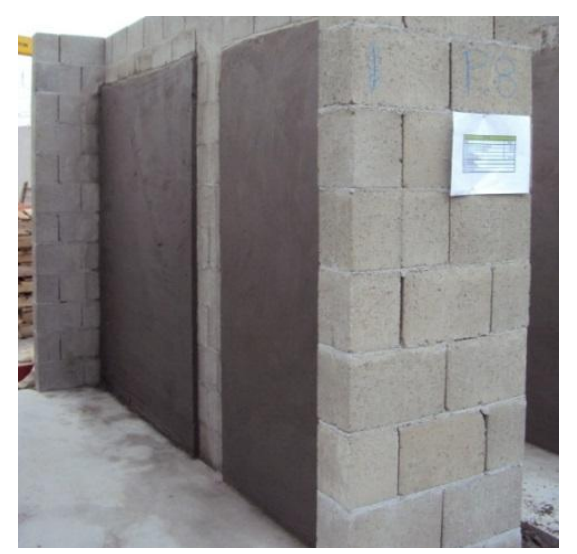

Figura 9 - Painéis executados em campo 
Tabela 2 - Caracterização da argamassa

\begin{tabular}{|c|c|c|c|}
\hline Característica avaliada & Método de ensaio & Idade & Resultados \\
\hline Retenção de água & NBR 13277 (ABNT, 2005a) & \multirow{2}{*}{ Argamassa fresca } & $76 \%$ \\
\hline Teor de ar incorporado & NBR 13278 (ABNT, 2005b) & & $10 \%$ \\
\hline Módulo de deformação & NBR 8522 (ABNT, 1984) & \multirow{3}{*}{28 dias } & $1,36 \mathrm{GPa}$ \\
\hline Resistência à tração & NBR 13279 (ABNT, 2005c) & & $1,3 \mathrm{MPa}$ \\
\hline Resistência à compressão & NBR 13279 (ABNT, 2005c) & & $5,2 \mathrm{MPa}$ \\
\hline
\end{tabular}

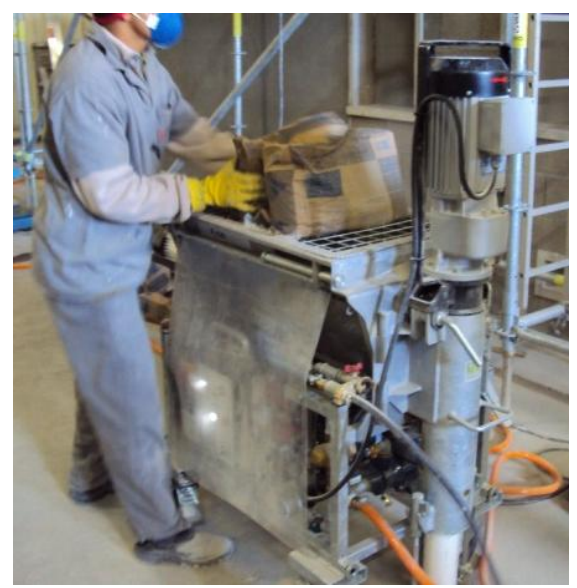

Figura 10 - Equipamento de mistura e projeção de argamassa utilizado

A espessura da camada de revestimento para todos os painéis foi fixada em $2 \mathrm{~cm}$ - obtida por taliscamento -, de forma a atender às exigências de espessura mínima estabelecida pela NBR 13749 (ABNT, 1996).

A caracterização da argamassa (Tabela 2) foi feita a partir de uma mistura do produto industrializado com $22 \%$ de água, como indicado pelo fabricante, empregando-se o mesmo equipamento utilizado em todo o programa experimental; em seguida, simulando-se as condições de aplicação sobre o substrato, foi bombeada e projetada em um recipiente, a partir do qual foi coletada para a confecção dos corpos de prova.

\section{Etapa 3: avaliação experimental em laboratório}

A segunda etapa envolveu a execução dos painéis $1 \mathrm{~L}$ a $15 \mathrm{~L}$, em laboratório, com o objetivo de identificar o potencial de emprego da argamassa proposta pelo fabricante parceiro. Por isso, buscouse isolar o efeito das condições ambientais, além de se ter avaliado somente o efeito das variáveis diretamente relacionadas às características da argamassa: número, espessura de demãos e intervalo entre elas, além do próprio tempo para realização do acabamento superficial, como identificado no Quadro 1.

Esses painéis empregaram argamassa com teor de água de $22 \%$ aplicada com o bico da pistola distante do substrato aproximadamente $15 \mathrm{~cm}$, formando cordões horizontais (Figura 11). Em seguida, realizou-se o alisamento da superfície com régua $\mathrm{H}$ (Figura 12), com posterior raspagem superficial (Figura 13) e desempeno manual do revestimento (Figura 14).

Nos painéis $1 \mathrm{~L}$ a $8 \mathrm{~L}$, a argamassa foi aplicada em uma demão (Figura 15) ou duas demãos (Figura 16). Neste caso, a primeira foi aplicada com aproximadamente $3 \mathrm{~mm}$, enquanto a segunda foi aplicada com aproximadamente $1,7 \mathrm{~cm}$ (totalizando os $2 \mathrm{~cm}$ ). Para esses painéis, o intervalo entre demãos foi de $24 \mathrm{~h}$, e o tempo para início do acabamento superficial foi em torno de $120 \mathrm{~min}$. 


\begin{tabular}{|c|c|c|c|c|c|c|c|c|c|c|c|c|}
\hline \multirow{2}{*}{ ¿્ّ } & \multicolumn{3}{|c|}{$\begin{array}{l}\text { Número e espessura de } \\
\text { demãos }\end{array}$} & \multicolumn{4}{|c|}{ Intervalo entre demãos } & \multicolumn{5}{|c|}{$\begin{array}{c}\text { Intervalo para acabamento superficial } \\
\text { (minutos) }\end{array}$} \\
\hline & $\begin{array}{c}(1) \\
\text { uma } \\
2 \mathrm{~cm}\end{array}$ & $\begin{array}{c}\text { (2) } \\
\text { duas } \\
0,3+1,7 \mathrm{~cm}\end{array}$ & $\begin{array}{c}\text { (3) } \\
\text { duas } \\
1+1 \mathrm{~cm} \\
\end{array}$ & $\begin{array}{c}1) \\
30 \\
\text { min }\end{array}$ & $\begin{array}{c}(2) \\
60 \\
\text { min }\end{array}$ & $\begin{array}{c}(3) \\
90 \\
\text { min }\end{array}$ & $\begin{array}{l}(4) \\
24 \mathrm{~h}\end{array}$ & $\begin{array}{l}1) \\
10 \\
\text { min }\end{array}$ & $\begin{array}{c}(2) \\
20 \\
\min \end{array}$ & $\begin{array}{l}3) \\
40 \\
\text { min }\end{array}$ & $\begin{array}{l}(4) \\
60 \\
\text { min }\end{array}$ & $\begin{array}{c}(5) \\
\sim 120 \mathrm{~min}\end{array}$ \\
\hline $1 \mathrm{~L}$ & & & $\mathrm{X}$ & & & & $\mathrm{X}$ & & & & & $X$ \\
\hline $2 \mathrm{~L}$ & & $X$ & & & & & $\bar{x}$ & & & & & $\bar{x}$ \\
\hline $3 \mathrm{~L}$ & & & $\mathrm{X}$ & & & & $\mathrm{X}$ & & & & & $\mathrm{X}$ \\
\hline $4 \mathrm{~L}$ & & $x$ & & & & & $x$ & & & & & $\mathrm{X}$ \\
\hline $5 \mathrm{~L}$ & $x$ & & & & & & & & & & & $\mathrm{X}$ \\
\hline $6 \mathrm{~L}$ & $\mathrm{X}$ & & & & & & & & & & & $x$ \\
\hline $7 \mathrm{~L}$ & $\mathrm{X}$ & & & & & & & & & & & $\bar{x}$ \\
\hline $8 \mathrm{~L}$ & $\mathrm{X}$ & & & & & & & & & & & $x$ \\
\hline $9 \mathrm{~L}$ & & & $x$ & $\mathrm{x}$ & & & & & & & & $\mathrm{x}$ \\
\hline $10 \mathrm{~L}$ & & & $\mathrm{X}$ & & $x$ & & & & & & & $\mathrm{X}$ \\
\hline $11 \mathrm{~L}$ & & & $\mathrm{X}$ & & & $\mathrm{X}$ & & & & & & $\mathrm{X}$ \\
\hline $12 \mathrm{~L}$ & & & $\mathrm{X}$ & $\mathrm{X}$ & & & & $\mathrm{X}$ & & & & \\
\hline $13 \mathrm{~L}$ & & & $x$ & $\bar{x}$ & & & & & $\mathrm{X}$ & & & \\
\hline $14 \mathrm{~L}$ & & & $\mathrm{X}$ & $\bar{X}$ & & & & & & $\mathrm{x}$ & & \\
\hline $15 \mathrm{~L}$ & & & $\mathrm{X}$ & $\bar{x}$ & & & & & & & $\bar{x}$ & \\
\hline
\end{tabular}

Quadro 1 - Variáveis atribuídas aos painéis $1 \mathrm{~L}$ a $15 \mathrm{~L}$ (laboratório)

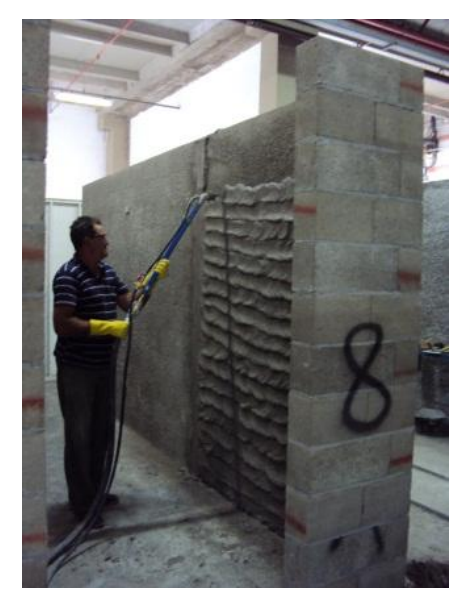

Figura 11 - Projeção

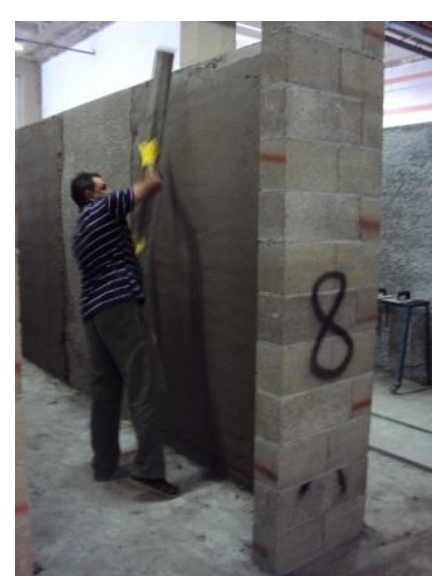

Figura 12 - Espalhamento 
Figura 13 - Raspagem

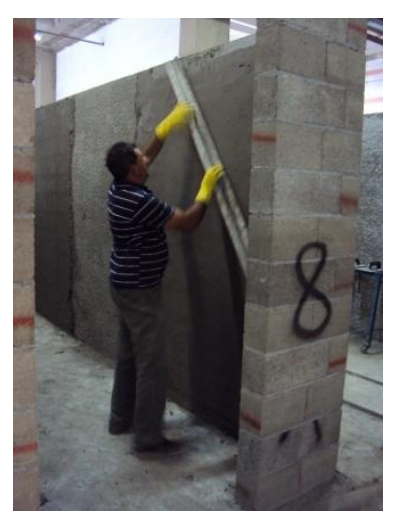

Figura 14 - Desempeno
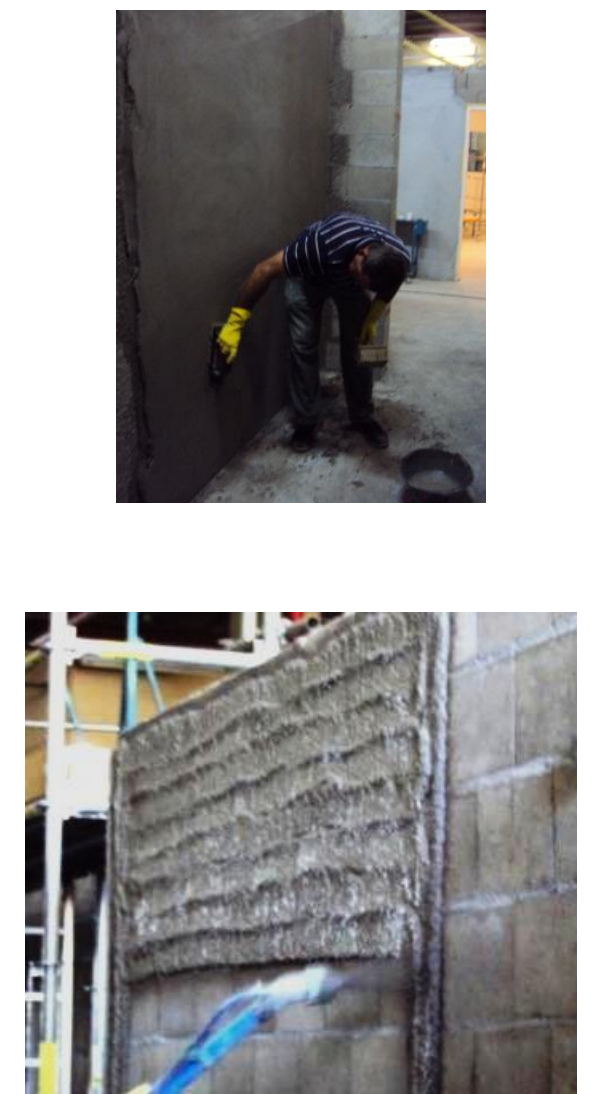

Figura 15 - Argamassa aplicada em uma demão

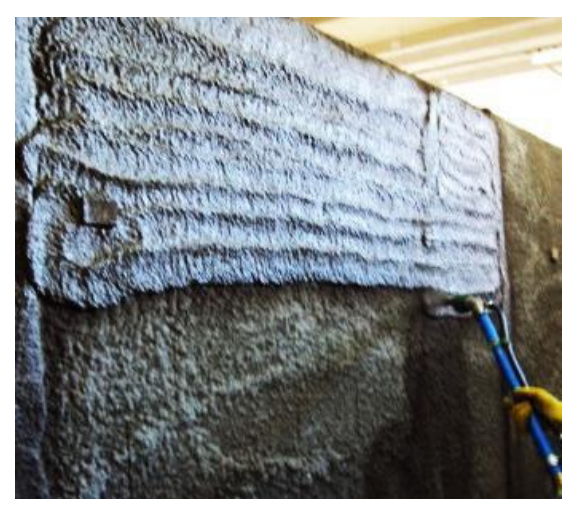

Figura 16 - Argamassa aplicada em duas demãos

94 Zanelatto, K. C,; Barros, M. M. S. B. de; Monte, R.; Sabbatini, F. H. 
Nos painéis 9L a 11L a argamassa foi aplicada em duas demãos (de aproximadamente $1 \mathrm{~cm}$ de espessura cada), com intervalo entre demãos variando em 30, 60 ou $90 \mathrm{~min}$, na técnica conhecida como "úmido sobre úmido". Nesses painéis não houve alteração no tempo de acabamento, de aproximadamente $120 \mathrm{~min}$.

Nos painéis $12 \mathrm{~L}$ a $15 \mathrm{~L}$, manteve-se o tempo de 30 min entre as duas demãos e variou-se o tempo para o acabamento superficial, adotando-se intervalos de $10,20,40,60$ (sarrafeamento) ou $120 \mathrm{~min}$ (raspagem).

\section{Etapa 4: Avaliação experimental em campo}

Nessa etapa foram produzidos os painéis 1C a $12 \mathrm{C}$, com o objetivo de verificar como as variáveis da técnica (Quadro 2) influenciariam no comportamento dos revestimentos executados sob as mesmas condições de uma fachada.
Os painéis $1 \mathrm{C}$ a $9 \mathrm{C}$ foram produzidos tal como os de laboratório, tendo-se variado o teor de água da argamassa $(22 \%, 25 \%$ ou $28 \%)$, a condição de umidade do substrato (seco ou umedecido $24 \mathrm{~h}$ antes, por aspersão de água com trincha) e o intervalo entre demãos $(0,5$ h ou $24 \mathrm{~h})$, em função das condições identificadas no levantamento de campo.

Nos painéis $10 \mathrm{C}$ a $12 \mathrm{C}$ foi mantida a condição de umidade do substrato (seco) e o intervalo entre demãos (24 h), tendo-se alterado a forma de aplicação da argamassa: lançamento manual (Figura 17), com desempenadeira (Figura 18) ou por projeção mecânica contínua (Figura 19). A mesma argamassa foi empregada com as três técnicas de aplicação, pois, segundo o fabricante, uma argamassa desenvolvida para projeção pode ser utilizada com aplicação manual; o contrário, porém, pode não ser verdadeiro, pois pode ser incompatível com o equipamento de projeção.

\begin{tabular}{|c|c|c|c|c|c|c|c|c|c|c|c|c|}
\hline \multirow[b]{2}{*}{ 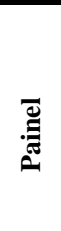 } & \multicolumn{3}{|c|}{$\begin{array}{c}\text { Teor de água de } \\
\text { argamassa }\end{array}$} & \multicolumn{2}{|c|}{$\begin{array}{c}\text { Condição de } \\
\text { umidade da } \\
\text { base }\end{array}$} & \multicolumn{2}{|c|}{$\begin{array}{c}\text { Intervalo } \\
\text { entre } \\
\text { demãos }\end{array}$} & \multicolumn{3}{|c|}{$\begin{array}{c}\text { Técnica de aplicação da } \\
\text { argamassa }\end{array}$} & \multicolumn{2}{|c|}{$\begin{array}{c}\text { Técnica de acabamento } \\
\text { superficial }\end{array}$} \\
\hline & $\begin{array}{l}(1) \\
22 \%\end{array}$ & $\begin{array}{l}(2) \\
25 \%\end{array}$ & $\begin{array}{l}(3) \\
28 \%\end{array}$ & $\begin{array}{l}(1) \\
\text { Seca }\end{array}$ & $\begin{array}{l}(2) \\
\text { Úmida }\end{array}$ & $\begin{array}{l}(1) \\
0,5 \mathrm{~h}\end{array}$ & $\begin{array}{l}(2) \\
24 \mathrm{~h}\end{array}$ & $\begin{array}{c}(1) \\
\text { Lança- } \\
\text { mento } \\
\text { manual }\end{array}$ & $\begin{array}{c}(2) \\
\text { Com } \\
\text { desempe- } \\
\text { nadeira }\end{array}$ & $\begin{array}{c}(3) \\
\text { Projeção } \\
\text { mecânica }\end{array}$ & $\begin{array}{c}(1) \\
\text { Sarrafea- } \\
\text { mento } \\
\text { tradicional }\end{array}$ & $\begin{array}{c}(2) \\
\text { Raspagem }\end{array}$ \\
\hline $1 \mathrm{C}$ & & $x$ & & & $x$ & $x$ & & & & $X$ & & $x$ \\
\hline $2 \mathrm{C}$ & $X$ & & & & $X$ & $x$ & & & & $x$ & & $x$ \\
\hline $3 \mathrm{C}$ & & $x$ & & & $X$ & & $\bar{x}$ & & & $\bar{X}$ & & $\bar{X}$ \\
\hline $4 \mathrm{C}$ & $X$ & & & & $x$ & & $x$ & & & $x$ & & $x$ \\
\hline $5 \mathrm{C}$ & & $x$ & & $x$ & & $x$ & & & & $\bar{X}$ & & $x$ \\
\hline $6 \mathrm{C}$ & $x$ & & & $X$ & & $X$ & & & & $X$ & & $x$ \\
\hline $7 \mathrm{C}$ & & $x$ & & $X$ & & & $x$ & & & $X$ & & $X$ \\
\hline $8 \mathrm{C}$ & $X$ & & & 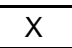 & & & $\bar{X}$ & & & $\bar{X}$ & & $\bar{X}$ \\
\hline $9 \mathrm{C}$ & & & $x$ & $x$ & & & $x$ & & & $x$ & & $x$ \\
\hline $10 \mathrm{C}$ & $x$ & & & $x$ & & & $x$ & $x$ & & & $x$ & \\
\hline $11 \mathrm{C}$ & & & $x$ & $X$ & & & $X$ & & $X$ & & $X$ & \\
\hline $12 \mathrm{C}$ & & & $x$ & $x$ & & & $x$ & & & $x$ & $x$ & \\
\hline
\end{tabular}

Quadro 2 - Variáveis atribuídas aos painéis de 1C a 12C (campo)

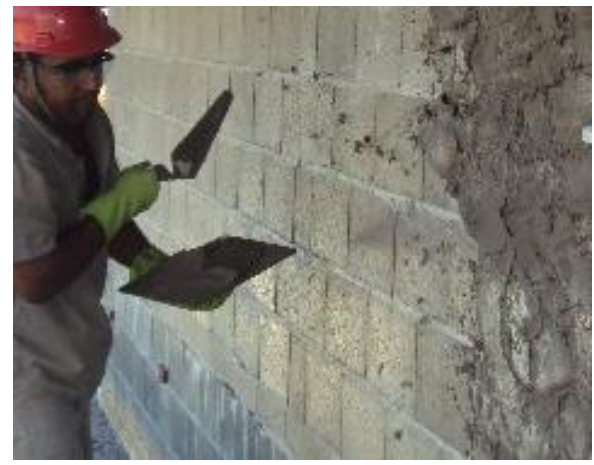

Figura 17 - Aplicação manual 


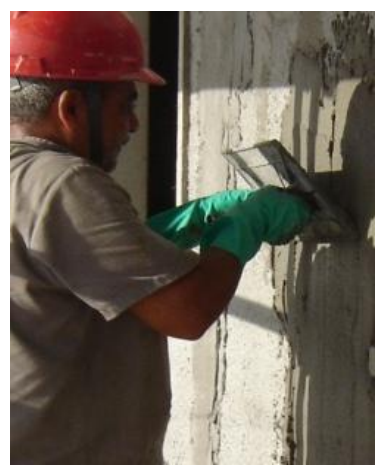

Figura 18 - Aplicação com desempenadeira

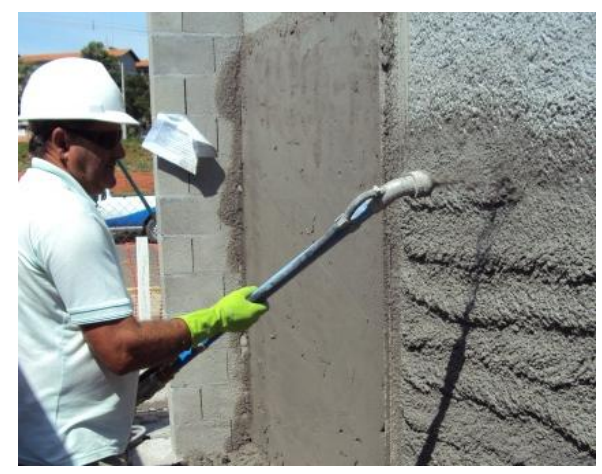

Figura 19 - Aplicação com projeção mecânica

Para a aplicação com desempenadeira e por projeção mecânica empregou-se teor de umidade de $28 \%$. No entanto, quando da aplicação manual, o teor de umidade foi reduzido para $22 \%$, para que se obtivesse a trabalhabilidade requerida pelo aplicador.

No acabamento empregaram-se técnicas tradicionais: sarrafeamento e desempeno superficial.

\section{Métodos de avaliação}

A adesão inicial foi avaliada visualmente, $\log 0$ após a projeção da argamassa sobre o substrato e durante as operações de execução do revestimento, identificando-se a ocorrência de ondulação ou escorregamento, fissuração ou destacamento da camada de argamassa após a aplicação.

A fissuração foi avaliada visualmente logo após a execução do painel e aos 28 dias, conforme prescrições da NBR 15575-4 (ABNT, 2012).

A aderência do revestimento ao substrato foi avaliada pelo ensaio de resistência de aderência à tração, aos 28 dias de idade (NBR 13528 (ABNT, 2010)). Em cada painel foram produzidos 12 corpos de prova, cortados a seco, espaçados entre si por, no mínimo, $50 \mathrm{~mm}$, distribuídos aleatoriamente (Figuras 20 a 22). Os dispositivos utilizados estão apresentados no Quadro 3.

A partir dos resultados individuais, obtidos através do ensaio de resistência de aderência, foram gerados gráficos de barra, nos quais estão apresentados, para cada painel de revestimento:

(a) a resistência potencial, correspondente ao maior valor obtido (CARASEK, 1996); a média geral;

(b) a média excluindo-se os valores $33 \%$ mais baixos (NBR 13749 (ABNT, 1996)); e

(c) a média considerando-se somente a ruptura na interface do revestimento de argamassa com o substrato (CARASEK, 1996).

Também foram apresentadas as porcentagens obtidas para cada tipo de ruptura do corpo de prova: interface do revestimento de argamassa com o substrato, superfície do revestimento e camada de revestimento (NBR 13528 (ABNT, 2010)).

\section{Resultados}

\section{Painéis executados em laboratório}

O Quadro 4 e as Figuras 23 e 24 apresentam os resultados obtidos na etapa de laboratório. 


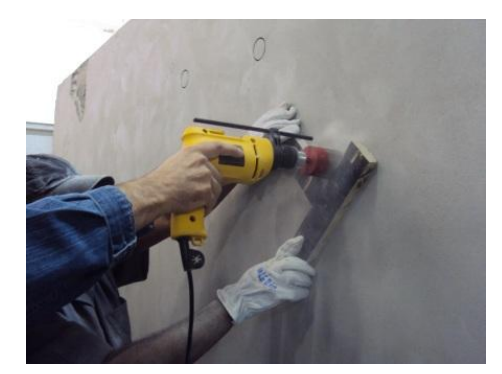

Figura 20 - Corte a seco

Figura 21 - Colagem das pastilhas
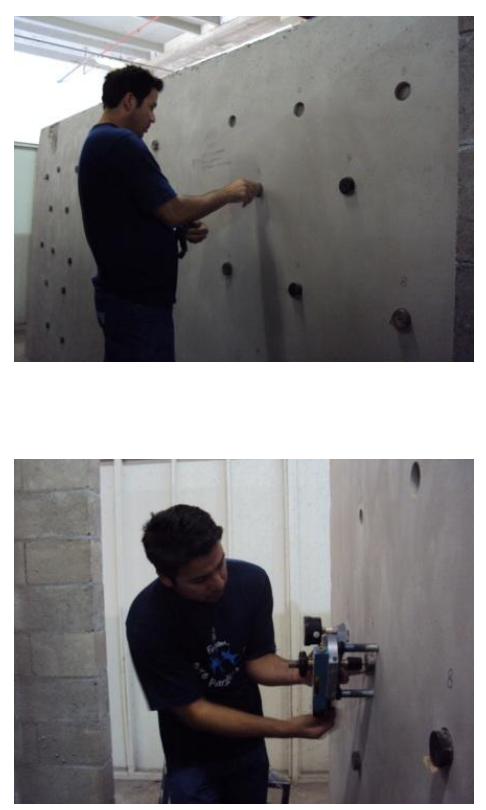

Figura 22 - Ensaio - tração direta

\begin{tabular}{|c|c|c|}
\hline Equipamento de tração & Pastilhas (seção) & Disco de corte \\
\hline Hidráulico - DYNA-PROCEQ & Alumínio com seção circular - $\Phi 50 \mathrm{~mm}$ & Serra-copo diamantada \\
\hline
\end{tabular}

Quadro 3 - Dispositivos empregados nos ensaios de resistência de aderência à tração

\begin{tabular}{|c|c|c|c|c|c|c|c|}
\hline \multirow{2}{*}{ 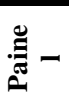 } & \multicolumn{3}{|c|}{ Número e espessura das demãos } & \multicolumn{4}{|c|}{ Efeitos no comportamento do revestimento } \\
\hline & $\begin{array}{l}\text { (1) uma } \\
2 \mathrm{~cm}\end{array}$ & $\begin{array}{c}\text { (2) duas } \\
0,3+1,7 \mathrm{~cm} \\
\end{array}$ & $\begin{array}{l}\text { (3) duas } \\
1+1 \mathrm{~cm}\end{array}$ & Destacamento & Escorregamento & Bolhas & $\begin{array}{c}\text { Fissuração } \\
\text { excessiva }\end{array}$ \\
\hline $1 \mathrm{~L}$ & & & $X$ & & & & \\
\hline $2 \mathrm{~L}$ & & $\bar{x}$ & & & & & $\bullet$ \\
\hline $3 \mathrm{~L}$ & & & $X$ & & & & \\
\hline $4 \mathrm{~L}$ & & $\mathrm{X}$ & & & & & $\bullet$ \\
\hline $5 \mathrm{~L}$ & $\mathrm{X}$ & & & & $\bullet$ & $\bullet$ & $\bullet$ \\
\hline $6 \mathrm{~L}$ & $\mathrm{X}$ & & & & $\bullet$ & $\bullet$ & $\bullet$ \\
\hline $7 \mathrm{~L}$ & $\mathrm{X}$ & & & & $\bullet$ & $\bullet$ & $\bullet$ \\
\hline $8 \mathrm{~L}$ & $\bar{X}$ & & & & $\bullet$ & $\bullet$ & $\bullet$ \\
\hline 9L & & & $\mathrm{X}$ & & & & \\
\hline $10 \mathrm{~L}$ & & & $\mathrm{X}$ & & & & \\
\hline $11 \mathrm{~L}$ & & & $\mathrm{X}$ & & & & \\
\hline $12 \mathrm{~L}$ & & & $\mathrm{X}$ & & & & \\
\hline $13 \mathrm{~L}$ & & & $\mathrm{X}$ & & & & \\
\hline $14 \mathrm{~L}$ & & & $\mathrm{X}$ & & & & \\
\hline $15 \mathrm{~L}$ & & & $X$ & & & & \\
\hline
\end{tabular}

Quadro 4 - Resultados da avaliação visual em laboratório

Avaliação da influência da técnica de execução no comportamento de revestimento de argamassa aplicado com 


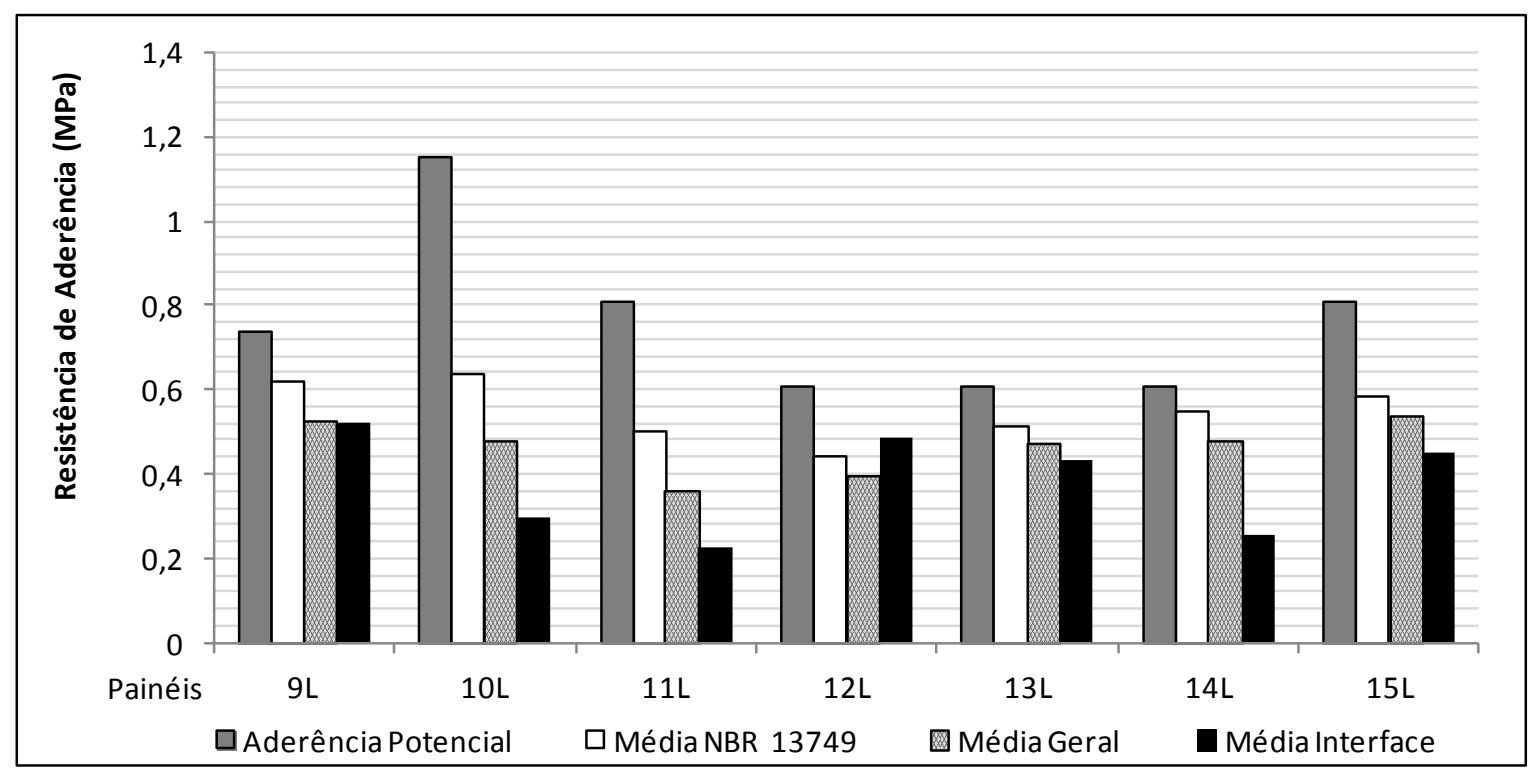

Figura 23 - Médias da resistência de aderência à tração dos corpos de prova de revestimento laboratório

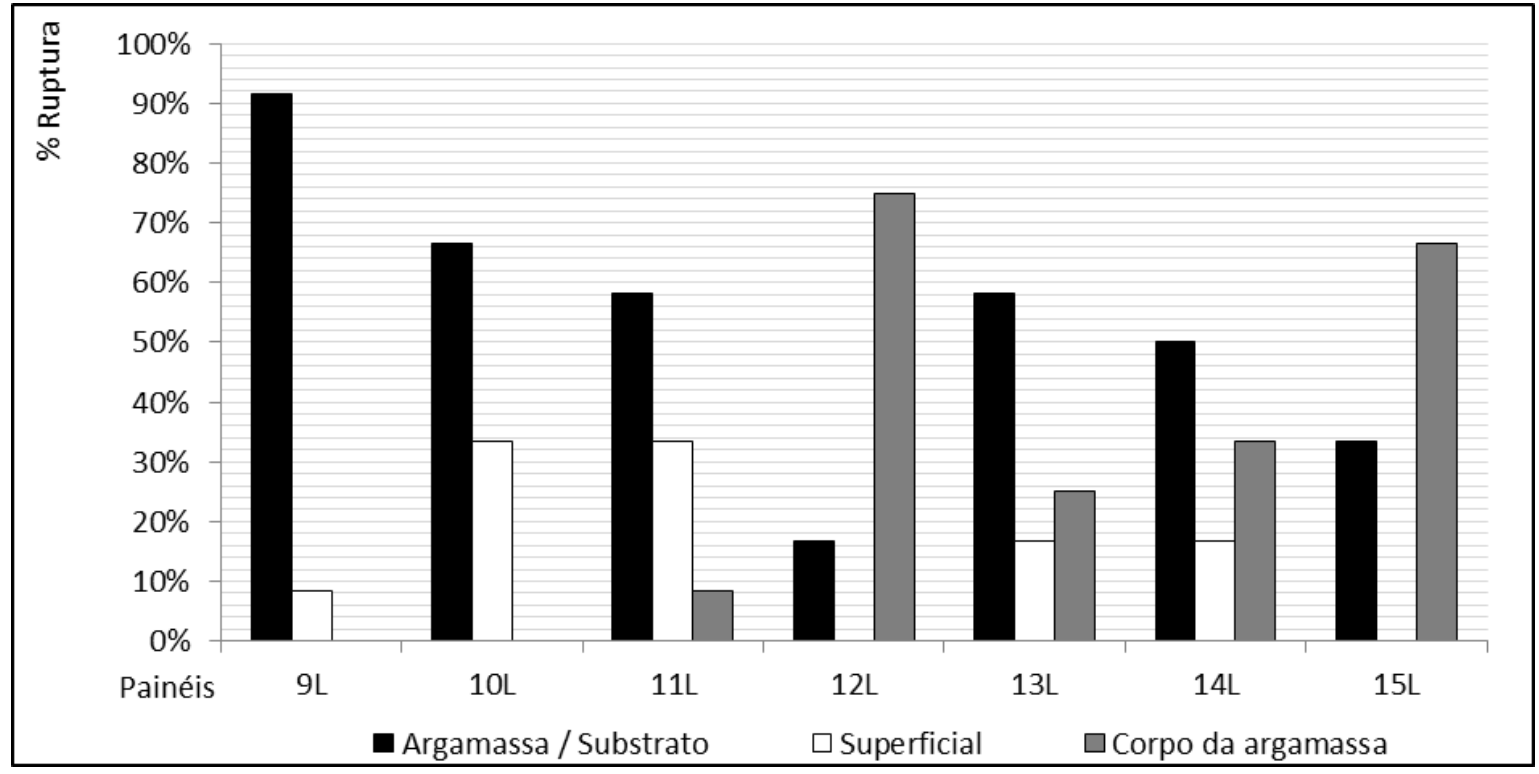

Figura 24 - Porcentual das formas de ruptura dos corpos de prova de revestimento - laboratório

Os painéis $1 \mathrm{~L}$ a $8 \mathrm{~L}$ apresentaram problemas relacionados à adesão inicial ou à fissuração excessiva. A técnica de aplicação em uma e duas demãos com espessuras próximas a $2 \mathrm{~cm}$ mostrouse inadequada para a argamassa e o substrato em questão; por isso, foi descartada, e esses painéis não foram ensaiados quanto à resistência de aderência.

Na Figura 23 estão apresentados os resultados do ensaio de resistência de aderência dos painéis $9 \mathrm{~L}$ a $15 \mathrm{~L}$, e na Figura 24 os dados relativos à porcentagem das três formas de ruptura dos corpos de prova para cada painel: interface entre argamassa e substrato, superficial ou na camada de revestimento.

Foram gerados gráficos box plot das variáveis apresentadas no Quadro 1 (Figura 25a e b), facilitando a visualização da variabilidade dos resultados.

Considerando-se as variáveis apresentadas no Quadro 1, aplicou-se a análise de variância ANOVA - aos resultados obtidos dos painéis 9L a 15L, utilizando-se o software MINITab, com nível de significância de 5\% (Tabela 3). 
(a)

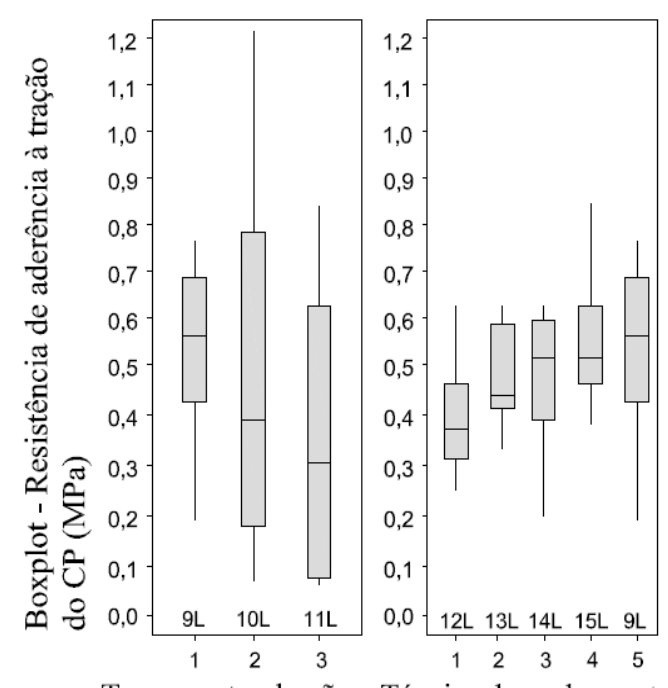

Tempo entre demãos Técnica de acabamento

Figura 25 - Resistência de aderência em função de: (a) tempo entre demãos em min (1) - 30; (2) - 60; (3) - 90 (b) intervalo para acabamento superficial em $\min (1)$ - 10; (2) - 20; (3) - 40; (4) - 60 e (5) - 120

Tabela 3 - Resultados da ANOVA da avaliação experimental em laboratório

\begin{tabular}{c|c|c}
\hline Painéis & Variáveis e combinações objeto de análise & Resultado (Valor P) \\
\hline 9L a 11L & Tempo entre demãos & $(\mathrm{P}=0,371>0,05){\text { Aceita } \mathrm{H}_{0}}$ \\
12L a 15L & Tempo para a realização do acabamento superficial & $(\mathrm{P}=0,061>0,05){\text { Aceita } \mathrm{H}_{0}}$ \\
\hline
\end{tabular}

$\mathrm{O}$ modelo da ANOVA adota a hipótese $\mathrm{H}_{0}$ de que as médias dos resultados obtidos são iguais $\left(\mathrm{H}_{0}\right.$ : $\mu 1=\mu 2=\mu 3=\mu)$, e, para testar a hipótese, calcula-se o valor P. Valores $\mathrm{P}$ menores do que o nível de significância adotado ( $5 \%$ ou 0,05$)$ indicam a rejeição de $\mathrm{H}_{0}$, isto é, as médias da variável estudada não são iguais, e valores $\mathrm{P}$ maiores ou iguais ao nível de significância adotado indicam aceitação de $\mathrm{H}_{0}$, isto é, as médias da variável estudada são iguais (COSTA NETO, 2002).

\section{Painéis executados em campo}

Em nenhum dos painéis executados em campo foram identificados problemas relacionados à adesão inicial ou problemas relacionados à fissuração excessiva durante ou após sua execução.

Os resultados de resistência de aderência obtidos na avaliação em campo estão apresentados nas Figuras 26 e 27.

Para a análise dos resultados de cada combinação de variáveis (Quadro 2), foram gerados gráficos box plot (Figura 28a, b e c) e aplicou-se o modelo de análise de variância, obtendo-se $\mathrm{o}$ valor $\mathrm{P}$ (Tabela 4), a partir do qual se aceita a hipótese $\left(\mathrm{H}_{0}\right)$ de que as médias são iguais $(\mathrm{P} \geq 0,05)$ ou ela é rejeitada $(\mathrm{P}<0,05)$. 


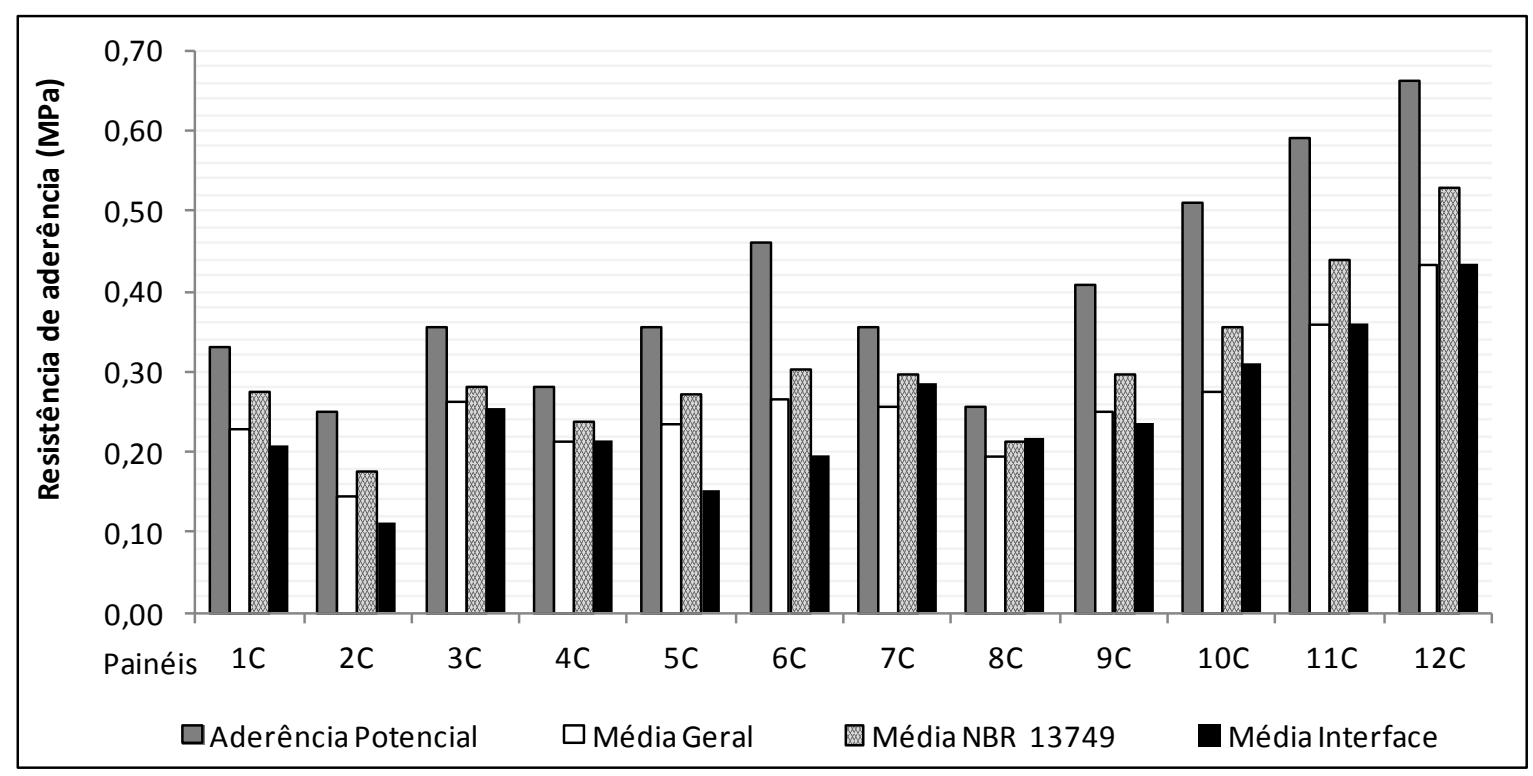

Figura 26 - Médias da resistência de aderência à tração dos corpos de prova de revestimento - canteiro

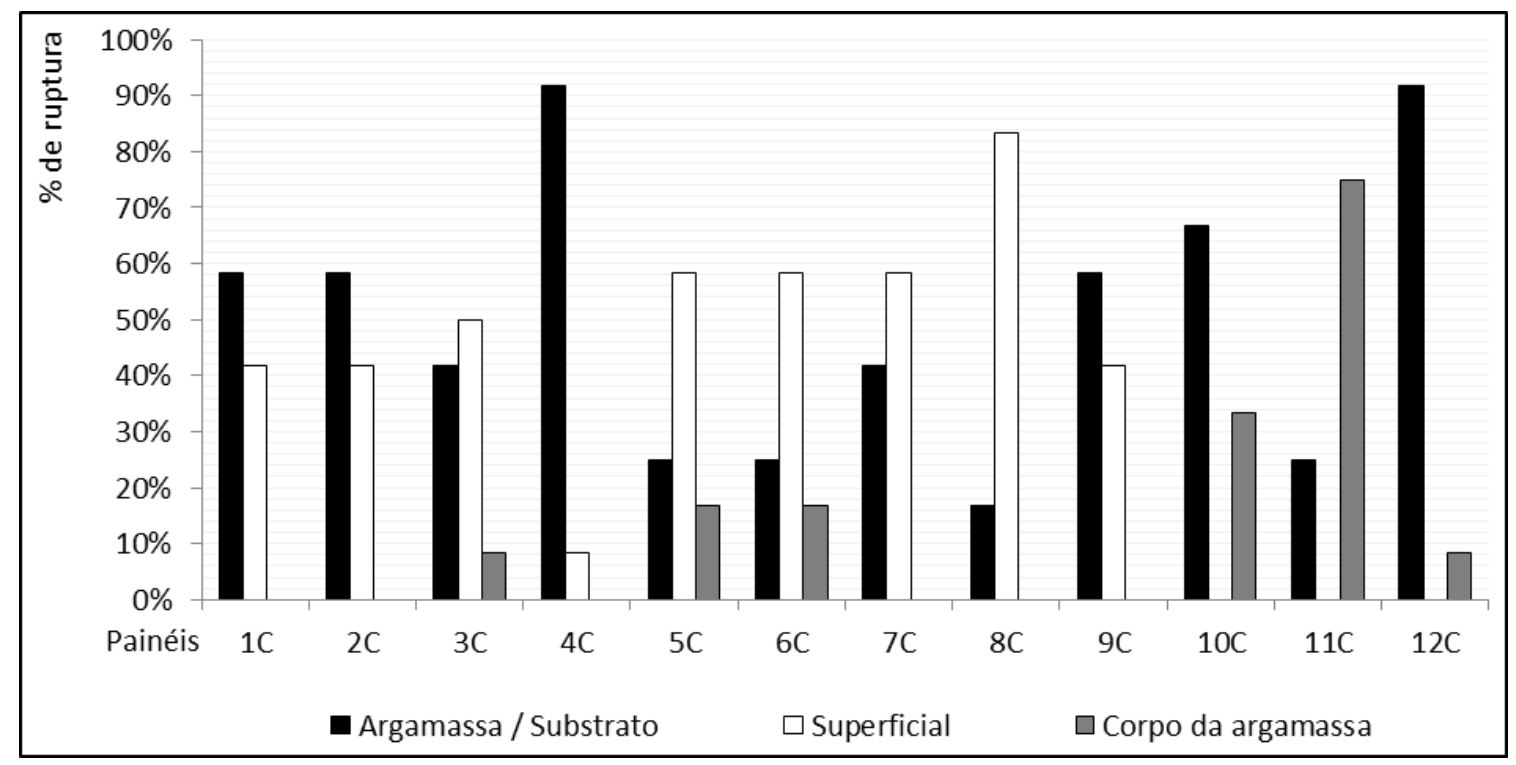

Figura 27 - Porcentual das formas de ruptura dos corpos de prova de revestimento - canteiro 
Tabela 4 - Resultados da ANOVA da avaliação experimental em campo

\begin{tabular}{|c|c|c|c|}
\hline Painéis & \multicolumn{2}{|c|}{ Variáveis e combinações objeto de análise } & Resultado (Valor P) \\
\hline \multirow{7}{*}{$1 \mathrm{C}$ a $8 \mathrm{C}$} & \multicolumn{2}{|c|}{ Teor de umidade da argamassa } & $(\mathrm{P}=0,011<0,05)$ Rejeita $\mathrm{H}_{0}$ \\
\hline & \multicolumn{2}{|l|}{ Condição de umidade do substrato } & $(\mathrm{P}=0,223>0,05)$ Aceita $\mathrm{H}_{0}$ \\
\hline & \multicolumn{2}{|l|}{ Intervalo entre demãos } & $(\mathrm{P}=0,068>0,05)$ Aceita $\mathrm{H}_{0}$ \\
\hline & \multicolumn{2}{|c|}{$\begin{array}{l}\text { Teor de umidade da argamassa x condição de umidade do } \\
\text { substrato }\end{array}$} & $(\mathrm{P}=0,012>0,05)$ Rejeita $\mathrm{H}_{0}$ \\
\hline & \multicolumn{2}{|c|}{ Teor de umidade da argamassa $\mathrm{x}$ intervalo entre demãos } & $(\mathrm{P}=0,074>0,05)$ Aceita $\mathrm{H}_{0}$ \\
\hline & \multicolumn{2}{|c|}{ Condição de umidade do substrato $\mathrm{x}$ intervalo entre demãos } & $(\mathrm{P}=0,035<0,05)$ Rejeita $\mathrm{H}_{0}$ \\
\hline & \multicolumn{2}{|c|}{$\begin{array}{l}\text { Teor de umidade da argamassa x condição de umidade do } \\
\text { substrato x intervalo entre demãos }\end{array}$} & $(\mathrm{P}=0,020<0,05)$ Rejeita $\mathrm{H}_{0}$ \\
\hline $10 \mathrm{C}$ a $12 \mathrm{C}$ & \multirow[t]{2}{*}{ Forma de aplicação da argamassa: } & $\begin{array}{l}\text { manual } \mathrm{x} \\
\text { desempenadeira } \mathrm{x} \\
\text { projeção mecânica }\end{array}$ & $(\mathrm{P}=0,063>0,05)$ Aceita $\mathrm{H}_{0}$ \\
\hline $10 \mathrm{C}$ e $12 \mathrm{C}$ & & $\begin{array}{l}\text { manual x projeção } \\
\text { mecânica }\end{array}$ & $(\mathrm{P}=0,028<0,05)$ Rejeita $\mathrm{H}_{0}$ \\
\hline $9 \mathrm{C}$ e $12 \mathrm{C}$ & \multicolumn{2}{|c|}{$\begin{array}{l}\text { Técnica de acabamento: espalhamento e raspagem } \mathrm{x} \\
\text { sarrafeamento tradicional }\end{array}$} & $(\mathrm{P}=0,005<0,05)$ Rejeita $\mathrm{H}_{0}$ \\
\hline
\end{tabular}

(a)

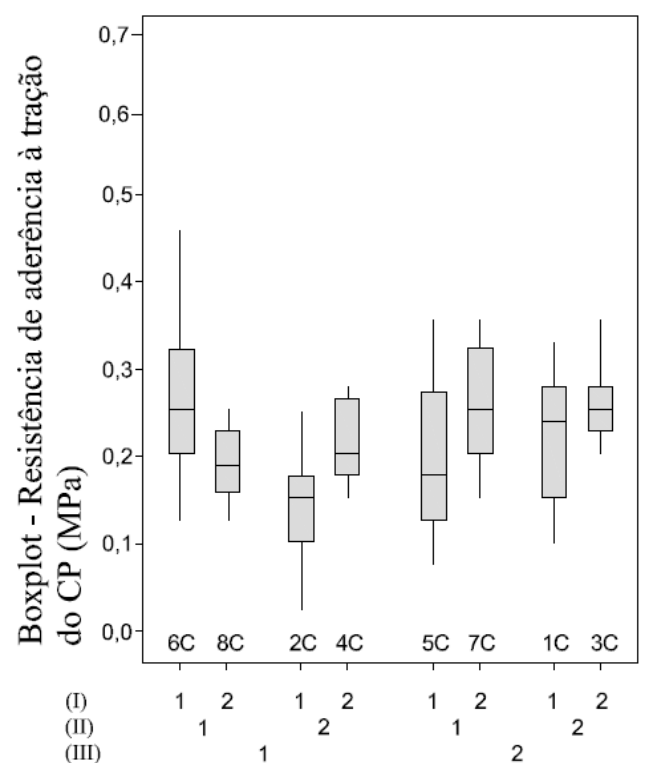

(I) Tempo entre demãos

(II) Umidade substrato

(III) Umidade argamassa (b)

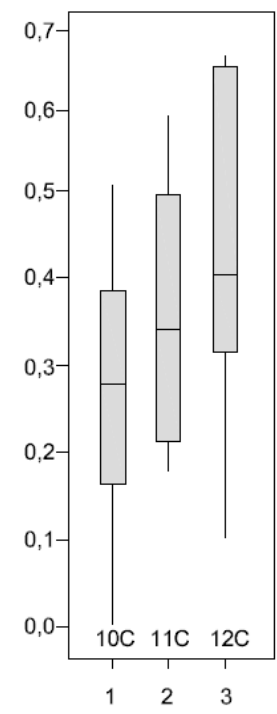

Forma de aplicação (c)

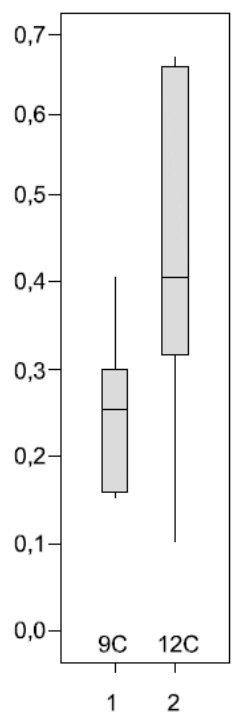

Técnica de acabamento

Figura 28 - Resistência de aderência em função de: (a) teor de umidade da argamassa x condição de umidade do substrato $x$ intervalo entre demãos; (b) forma de aplicação da argamassa (c) técnica de acabamento superficial

Nota: Legenda:

(a) (I) tempo entre demãos: 1 - 0,5 h e 2 - 24 h;

(II) condição de umidade do substrato: 1 - seco e 2 - úmido; e

(III) umidade da argamassa: 1 - 22\% e 2 - 25\%.

(b) forma de aplicação da argamassa: 1 - manual, 2 - com desempenadeira e 3 - projeção mecânica; e

(c) técnica de acabamento da superfície: 1 - raspagem e 2 - sarrafeamento tradicional. 


\section{Análise dos resultados}

\section{Número e espessura das demãos}

Verifica-se pelo Quadro 4 que todos os painéis executados com uma demão de $\operatorname{argamassa}(5 \mathrm{~L}$ a 8L) apresentaram problemas relacionados à perda da adesão inicial, como escorregamento da camada (Figura 29), aparecimento de ondulação (Figura 30) e fissuração do revestimento (Figuras 31 e 32). Os painéis executados com duas demãos (1L a $4 \mathrm{~L}$ e 9L a 15L) apresentaram pouca incidência desses problemas, que ocorreram somente nos painéis em que a segunda demão era mais espessa (aproximadamente 1,7 cm) (2L e 4L).

Situação similar é encontrada no trabalho de Santos (2003), que, ao avaliar painéis de revestimento sobre alvenarias de blocos de concreto, sem chapisco e com espessura de $2 \mathrm{~cm}$, com argamassa aplicada por projeção mecânica contínua em duas demãos, na técnica úmido sobre úmido, também identificou problemas relacionados à adesão inicial, caracterizados pelo "escorregamento" da argamassa. Essa autora afirma que tal comportamento é devido às propriedades reológicas da argamassa, à espessura da camada e às propriedades do substrato, como absorção inicial, porosidade e rugosidade.

Essa afirmativa é corroborada pelos resultados deste trabalho, particularmente quanto à influência da espessura da camada no comportamento do revestimento no estado fresco. Nos painéis $2 \mathrm{~L}$ e $4 \mathrm{~L}$ a 8L (Quadro 4), que apresentaram problemas de adesão inicial, a argamassa tinha $22 \%$ de umidade, tal como a utilizada nos painéis $2 \mathrm{C}, 4 \mathrm{C}, 6 \mathrm{C}, 8 \mathrm{C}$ e $10 \mathrm{C}$, que não apresentaram esses problemas. Por sua vez, os painéis em que a espessura de $2,0 \mathrm{~cm}$ foi dividida em duas demãos de $1,0 \mathrm{~cm}$ não apresentaram manifestações de ausência de adesão inicial (laboratório ou campo), ou seja, os resultados obtidos evidenciam que a espessura da camada é fundamental no comportamento do revestimento.

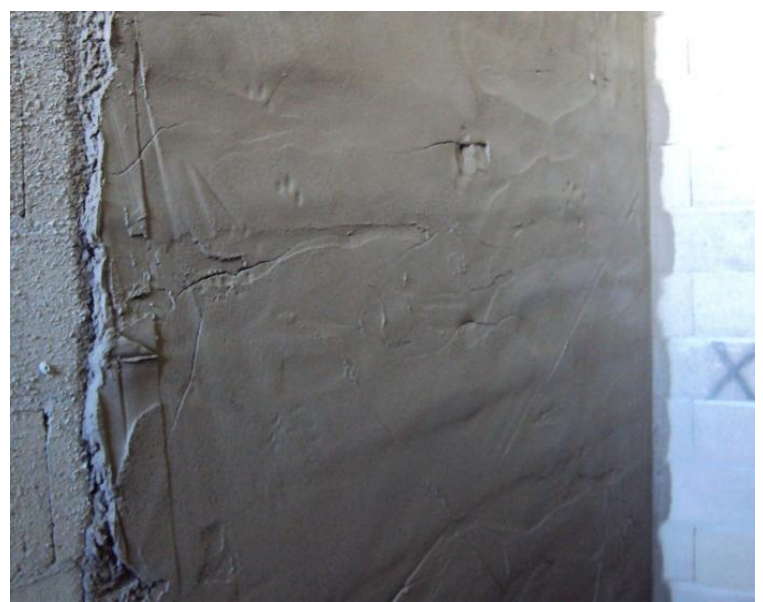

Figura 29 - Escorregamento da camada de argamassa - painel 5L

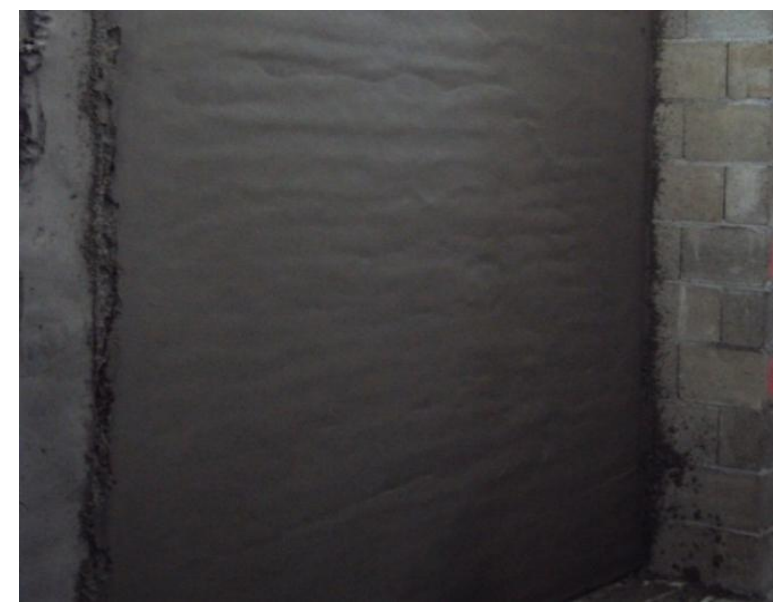

Figura 30 - Ondulação na camada de argamassa - painel 6L

102 Zanelatto, K. C,; Barros, M. M. S. B. de; Monte, R.; Sabbatini, F. H. 


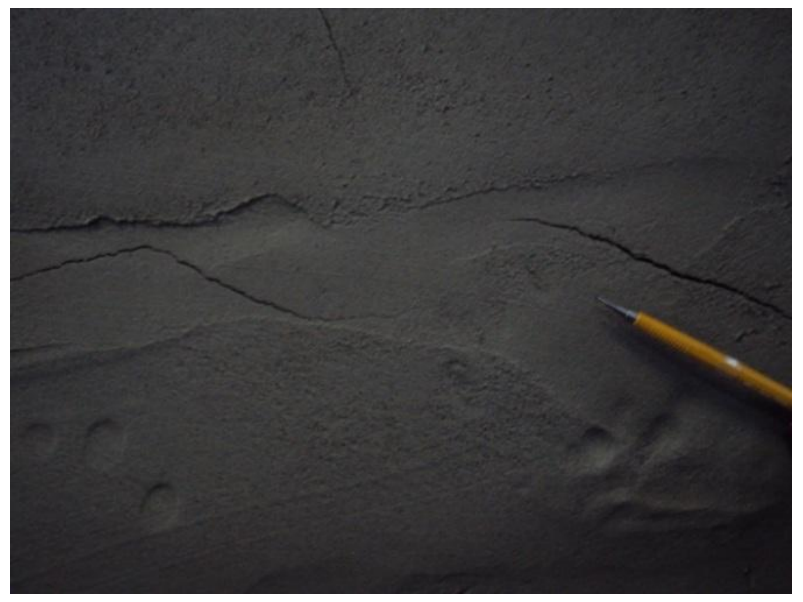

Figura 31 - Fissuras horizontais: escorregamento da camada de argamassa - painel 7L

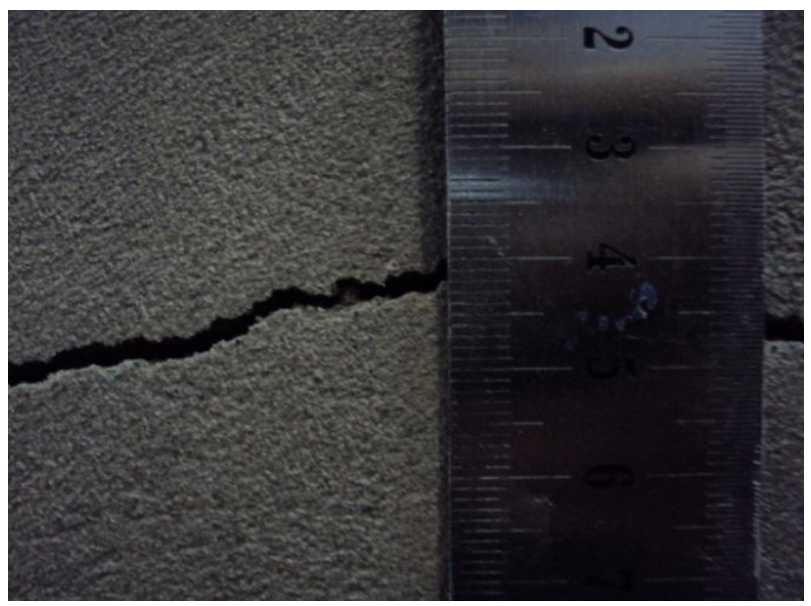

Figura 32 - Fissuras no revestimento - painel 8L

\section{Intervalo entre demãos}

Ao aumentar o intervalo entre demãos, na técnica úmido sobre úmido (Quadro 1), identificou-se a diminuição da média das resistências de aderência $(9 \mathrm{~L} \rightarrow$ 10L: 9\%; 9L $\rightarrow$ 11L: $31 \%$; 10L $\rightarrow 11 \mathrm{~L}:$ $24 \%$ ) (Figura 23) e o aumento da variabilidade dos resultados obtidos (Figura 25a).

Ao avaliar a influência desta variável em campo (Quadro 2), na técnica úmido sobre úmido $(0,5 \mathrm{~h})$ (1C, 2C, 3C, 4C) ou úmido sobre seco $(24 \mathrm{~h})$ (demais painéis), identifica-se que, em geral, houve um aumento das resistências de aderência (Figura 26) e diminuição da variabilidade dos resultados (Figura 28a) para o maior intervalo entre demãos.

A influência do aumento do intervalo entre demãos foi mais evidente na condição de menor teor de umidade da argamassa (22\%), com um aumento de $35 \%(2 \mathrm{C} \rightarrow 4 \mathrm{C})$ no caso do substrato umedecido e uma diminuição de $36 \%(6 \mathrm{C} \rightarrow 8 \mathrm{C})$ no caso do substrato seco. Para o teor de umidade da argamassa mais alto (25\%), o aumento do intervalo entre demãos resultou em um pequeno aumento na resistência de aderência, em ambas as situações $(5 \mathrm{C} \rightarrow 7 \mathrm{C}: 9 \% ; 1 \mathrm{C} \rightarrow 3 \mathrm{C}: 2 \%)$, indicando que o intervalo entre demãos interage fortemente com a condição de umidade do substrato e com o teor de umidade da argamassa (Figura 28a).

Aplicando-se a ANOVA (Tabela 3), identificou-se que não houve efeito estatisticamente significativo dessa variável isolada, ou seja, ainda que, aparentemente, o tempo entre demãos na técnica úmido sobre úmido tenha efeito sobre a resistência de aderência, isso não é confirmado estatisticamente, segundo o nível de significância adotado. No entanto, foi possível identificar, na aplicação em campo (Tabela 4), que a interação dessa variável com a condição de umidade do substrato e com o teor de umidade da argamassa mostrou-se estatisticamente significativa, confirmando a interação identificada a partir da leitura das Figuras 26 e 28a. 
Conclui-se que o aumento do intervalo entre demãos (úmido sobre úmido para úmido sobre seco) pode ser benéfico em situações em que o substrato está úmido ou em que se trabalha com argamassas com alto teor de água, não sendo recomendável para situações em que o substrato esteja seco e em que se trabalhe com argamassas com baixos teores de água.

\section{Intervalo para acabamento superficial}

A partir das Figuras 23 e 25b é possível verificar que, ao aumentar o tempo para a realização do acabamento superficial, houve o aumento das médias das resistências de aderência avaliadas $(12 \mathrm{~L} \rightarrow 13 \mathrm{~L}: 16 \%$; 13L $\rightarrow$ 14L: 7\%; 14L $\rightarrow$ 15L: $7 \%$ e $15 \mathrm{~L} \rightarrow 9 \mathrm{~L}: 6 \%$; $12 \mathrm{~L} \rightarrow$ 9L: $40 \%$ ).

Apesar disso, a ANOVA (Tabela 3) indica que o efeito da variável não é estatisticamente significativo na resistência de aderência.

As resistências de aderência mais baixas em painéis nos quais o acabamento superficial foi realizado em intervalo precoce possivelmente ocorreram porque o revestimento foi submetido a esforços - principalmente de cisalhamento quando a camada ainda não era capaz de suportálos, levando à ruptura da interface entre o material e o substrato. Essa mesma situação foi identificada por Santos (2003).

Os resultados obtidos nesta pesquisa confirmam a importância identificada por Baía e Sabbatini (2000) de se respeitar o período necessário para que a argamassa perca parte da água de amassamento para o substrato - ponto de sarrafeamento - e, por consequência, tenha início o ganho de resistência mecânica da interface, antes de se iniciarem as operações de acabamento superficial da camada de argamassa.

\section{Teor de umidade da argamassa}

Verifica-se, pelas Figuras 26, 27 e 28a, que o aumento do teor de água da argamassa de $22 \%$ para $25 \%$ provocou aumento da média das resistências de aderência $(8 \mathrm{C} \rightarrow 7 \mathrm{C}: 39 \% ; 2 \mathrm{C} \rightarrow$ 1C: $56 \% ; 4 \mathrm{C} \rightarrow 3 \mathrm{C}: 19 \%)$ e da variabilidade, confirmando resultados de Costa et al. (2010) de que o aumento no teor de água das argamassas estudadas possibilitou ganhos na resistência de aderência da ordem de $29 \%$, apesar do aumento da relação água/cimento.

Há um limite estreito na variação do teor de água da argamassa que leva a uma reologia adequada para aplicação com os sistemas de projeção mecânica contínua. Silva (2006), ao estudar as propriedades de argamassas com fibras, verificou que o aumento do teor de água de apenas $1 \%$ foi suficiente para provocar diferenças nas propriedades das argamassas - facilitou as operações de execução - e no revestimento, que teve sua resistência de aderência aumentada.

Os resultados da ANOVA (Tabela 4) confirmam o efeito estatisticamente significativo dessa variável isolada, reforçando que a reologia da argamassa deve ser adequada às condições do substrato e às condições de aplicação.

\section{Condição de umidade do substrato}

A alteração da condição de umidade do substrato, passando de seco para umedecido $24 \mathrm{~h}$ antes da execução do revestimento (Quadro 2), não mostrou uma tendência clara de diminuição ou aumento da média das resistências de aderência $(6 \mathrm{C} \rightarrow 2 \mathrm{C}:-$ $42 \%$; $8 \mathrm{C} \rightarrow 4 \mathrm{C}:+10 \%$; $5 \mathrm{C} \rightarrow 1 \mathrm{C}:+1 \%$; $7 \mathrm{C} \rightarrow 3 \mathrm{C}:$ $-5 \%$ ) (Figura 26). Segundo Scartezini et al. (2002), a alteração das características do substrato com relação à absorção de água resulta em mudança no comportamento dos revestimentos diante do mecanismo de aderência e, de forma geral, quanto maior o coeficiente de absorção da base, maior a resistência de aderência. Nesta pesquisa, o umedecimento do substrato $24 \mathrm{~h}$ antes da aplicação do revestimento parece não ter influenciado na resistência de aderência do revestimento, exceto nos painéis $6 \mathrm{C}$ e $2 \mathrm{C}$, que foram produzidos com a argamassa de teor de umidade mais baixo (22\%).

Aplicando-se o método ANOVA (Tabela 4) para esta variável isolada, os resultados não se mostraram estatisticamente significativos para $o$ nível de significância adotado, ou seja, a tendência de resistência de aderência seria a mesma para ambas as condições de umidade do substrato, o que permitiria maior flexibilidade à produção, que poderia ocorrer, por exemplo, posteriormente a períodos de grande estiagem ou de chuva.

Houve, também, redução da ruptura superficial em todas as situações avaliadas $(6 \mathrm{C} \rightarrow 2 \mathrm{C}:-38 \%$; $8 \mathrm{C}$ $\rightarrow 4 \mathrm{C}:-937 \%$; 5C $\rightarrow$ 1C: $-38 \%$; 7C $\rightarrow 3 \mathrm{C}:-$ $16 \%$ ) (Figuras 27 e 28a), o que pode estar relacionado à melhor condição para hidratação do cimento, uma vez que, possivelmente, a camada de argamassa tenha perdido menos água para o substrato previamente umedecido.

\section{Forma de aplicação da argamassa}

Pelas Figuras 26 e 28 b verifica-se que a alteração da técnica de aplicação com lançamento manual para aplicação com desempenadeira e dessa para a projeção mecânica apresentou resultados crescentes das médias de resistência $(10 \mathrm{C} \rightarrow 11 \mathrm{C}$ : $24 \% ; 11 \mathrm{C} \rightarrow 12 \mathrm{C}: 21 \% ; 10 \mathrm{C} \rightarrow 12 \mathrm{C}: 50 \%)$. 
Aumento similar foi identificado por outros trabalhos, nos quais se aponta o crescimento da resistência de aderência de 55\% (DUIABILE; CAVANI; OLIVEIRA, 2005) e 58\% (FERNANDES et al., 2009), em relação aos valores obtidos com a aplicação manual.

O aumento das resistências, no entanto, foi acompanhado de um aumento da variabilidade dos resultados $(11 \mathrm{C} \rightarrow 10 \mathrm{C} \rightarrow 12 \mathrm{C})$, tal como identificado por Fernandes et al. (2009) ao estudarem os sistemas de projeção a ar comprimido.

Pela ANOVA (Tabela 4), é possível verificar que a interação entre a aplicação com lançamento manual e mecânica mostrou-se estatisticamente significativa, o que indica que, quando possível, deve-se privilegiar a aplicação por projeção mecânica, pois propicia melhores condições de resistência de aderência.

A Figura 27 permite concluir, para os painéis 10C, $11 \mathrm{C}$ e $12 \mathrm{C}$, que não ocorreu ruptura superficial do revestimento, indicando que a forma de aplicação da argamassa não influencia nessa propriedade. Por outro lado, no painel 11C (desempenadeira) verifica-se que há um aumento expressivo de ruptura no corpo do revestimento, indicando possível falha na técnica de aplicação com desempenadeira em duas demãos. Esse resultado indica a importância de se desenvolverem argamassas que considerem a técnica de aplicação como um todo.

\section{Técnica de acabamento da camada}

Variando-se apenas a técnica de acabamento superficial do revestimento, de alisada e raspada (9C) para sarrafeada, segundo a técnica tradicional (12C), os resultados apresentaram aumento no valor médio de resistência de aderência (78\%), porcentagem de ruptura superficial nula e maior variabilidade nos resultados (Figuras 26, 27 e 28c).

É possível observar, também, pelas Figuras 26, $28 \mathrm{a}$ e 28c, que os painéis $10 \mathrm{C}$ a $12 \mathrm{C}$ (sarrafeamento) apresentam resistência de aderência visivelmente superior à apresentada pelos painéis 1C a 9C (raspagem). Pela ANOVA (Tabela 4), a técnica de acabamento mostrou-se estatisticamente significativa.

Sabbatini (1990) explica que a correta técnica de aplicação pode resultar no aumento da aderência dos revestimentos, em função das operações de compactação e prensagem, que tendem a ampliar a extensão de contato.

Verifica-se ainda (Figura 27) que, enquanto nos painéis $1 \mathrm{C}$ a $9 \mathrm{C}$ as porcentagens dos corpos de prova com ruptura superficial apresentam valores de $8 \%$ (4C) a $83 \%$ (8C), nos painéis $11 \mathrm{C}$ a $13 \mathrm{C}$ nenhum corpo de prova rompeu superficialmente. Possivelmente essa situação tenha ocorrido porque nos painéis $1 \mathrm{C}$ a $9 \mathrm{C}$, onde foi realizada a raspagem, foi necessário aspergir maior quantidade de água para realizar o desempeno do que nos painéis onde foi realizado o sarrafeamento tradicional (10C a 12C), que era realizado mais cedo. O maior teor de água superficial tende a reduzir a resistência mecânica e, portanto, elevar o número de rupturas nessa região.

\section{Interação entre as variáveis}

As combinações das variáveis umidade da argamassa, condição de umidade do substrato e intervalo entre demãos (Tabela 4) apresentam efeito estatístico nos resultados, indicando a importância da interação entre as variáveis na resistência de aderência do revestimento, como identificados por Costa et al. (2010) e Fernandes et al. (2009).

Os painéis que apresentaram as maiores médias de resistência de aderência foram os executados com sarrafeamento tradicional (painel 10C, 11C e 12C) (Figura 26), indicando influência positiva desta técnica no comportamento do revestimento.

Entre os painéis $1 \mathrm{C}$ a $9 \mathrm{C}$, os que apresentaram as maiores médias de resistência de aderência foram 6C, 7C e 9C, executados com a base seca; dois deles com teores de água mais altos $(7 \mathrm{C}-25 \%$ e $9 \mathrm{C}-28 \%$ ) e tempo entre demãos de $24 \mathrm{~h}$ (Figura 28a). O painel $6 \mathrm{C}$ foi executado com teor de água de $22 \%$, mas com tempo entre demãos de 0,5 h.

As médias de resistência de aderência mais baixas foram obtidas com os painéis $2 \mathrm{C}, 4 \mathrm{C}$ e $8 \mathrm{C}$, executados com teor de umidade da argamassa de $22 \%$. Entre eles, dois com a base úmida, com intervalo entre demãos diferente $(8 \mathrm{C}-0,5 \mathrm{~h}$ e $4 \mathrm{C}-$ $24 \mathrm{~h}$ ). O painel $2 \mathrm{C}$ foi executado com a base seca e com intervalo entre demãos de $24 \mathrm{~h}$.

Observou-se que, nas condições avaliadas neste estudo, uma argamassa com teor de água que propicie bombeamento, projeção e adesão inicial adequados, mesmo que associada a substrato seco, pode resultar em resistência de aderência adequada, ao menos para pequenas espessuras de revestimento.

\section{Influência das condições de exposição do painel}

Neste estudo, ao se compararem os resultados obtidos nos painéis 9L e 6C (Figura 33), nos quais foram aplicadas as mesmas variáveis, identificamse valores de resistência de aderência 
significativamente inferiores nos painéis expostos às condições ambientais externas $(9 \mathrm{~L} \rightarrow 6 \mathrm{C}$ : $52 \%$ ), indicando que o revestimento aplicado em condições ambientes pode apresentar resistência de aderência significativamente inferior aos painéis executados em laboratório, em que as condições climáticas estão sob controle.

Essa constatação permite afirmar que, ao se desenvolverem produtos para fachada, as avaliações não devem se limitar a condições climáticas de laboratório, usualmente controladas. Além disso, indica a necessidade de cuidados quando da aplicação de revestimentos de base cimentícia em condições ambiente; a cura do revestimento, por exemplo, pode ser de grande importância quanto mais agressivas forem as condições (CÂNDIA; FRANCO, 1998).

\section{Recomendações para execução de revestimentos de argamassa aplicada com projeção mecânica contínua}

Feitas as devidas análises de resultados deste estudo, é possível propor as seguintes recomendações para a execução dos revestimentos de argamassa aplicados com projeção mecânica contínua.
A primeira delas se refere à definição da argamassa, que deve considerar, além das propriedades exigidas para o bombeamento $\mathrm{e}$ projeção, as relacionadas à adesão inicial ao substrato, de forma a permitir a aplicação de espessuras maiores de argamassa, evitando diversas demãos, para que não se comprometa a produtividade dos serviços.

Essa avaliação, feita a partir da produção de painéis-teste com a espessura desejada de revestimento, servirá para identificar o potencial de fissuração e a resistência de aderência média do revestimento.

Sendo a aderência do revestimento uma de suas propriedades mais importantes e sabendo-se que depende das condições em que a argamassa é aplicada (FERNANDES et al., 2007), recomendase potencializar a extensão de aderência, que pode ser obtida com a projeção mecânica ou, quando da aplicação manual, com a compressão da argamassa.

Ao se utilizar a aplicação mecânica contínua, recomenda-se que, após o alisamento superficial com régua $\mathrm{H}$, a camada de argamassa não seja solicitada até que adquira condições de sofrer as operações de acabamento superficial, evitando prejudicar a aderência dos revestimentos, tal como no sarrafeamento.

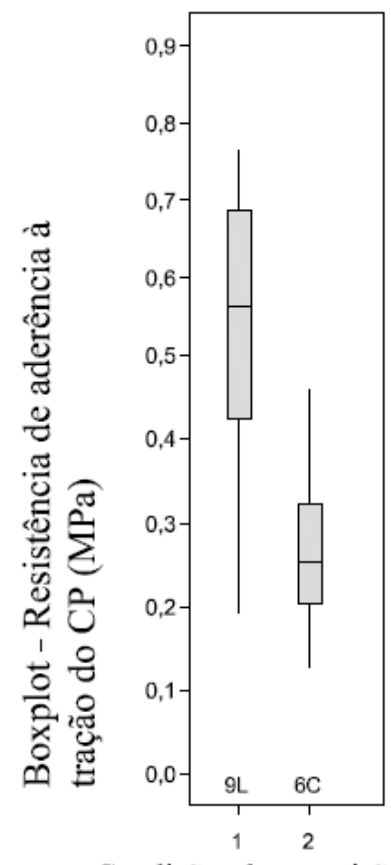

Condições de exposição

Figura 33 - Resistência de aderência em função das condições de exposição do painel: laboratório x campo 
Além disso, observou-se que, quando se empregou a técnica de sarrafeamento tradicional, os valores de resistência de aderência foram expressivamente superiores aos obtidos com a técnica de raspagem, além de se ter porcentagem de ruptura superficial nula. Esses fatos indicam que a técnica do sarrafeamento pode resultar em revestimentos de maior resistência mecânica que a técnica de raspagem. Entretanto, devido ao reduzido número de painéis avaliados para comparação dos resultados em relação a essa variável, não é possível afirmar que uma técnica é melhor que a outra. Assim, recomenda-se que a influência dessas variáveis seja mais bem avaliada em estudos futuros.

\section{Considerações finais}

Identificou-se que para determinada técnica de aplicação os fatores de maior influência na adesão inicial e na fissuração dos revestimentos são o teor de água das argamassas (associado à reologia) e a espessura da camada, que, quanto maior, menor a adesão inicial. Além disso, outras variáveis da técnica de execução, tais como o intervalo entre demãos, a condição de umidade do substrato e a técnica de acabamento da camada, podem interagir com aqueles dois fatores, levando a comportamento distinto do revestimento, principalmente em relação a sua resistência de aderência.

Essas variáveis da técnica de execução do revestimento podem assumir diferentes configurações no canteiro de obras. Assim, seleção de técnicas adequadas ao processo de produção de revestimentos de argamassa que considerem as propriedades dos materiais utilizados, bem como as condições de produção proporcionadas pelos equipamentos mecânicos e as diversas variáveis presentes no processo são um importante passo para se mitigarem problemas comumente identificados nos revestimentos de edifícios como fissuras e destacamentos.

Destaca-se, ainda, a interação de todas as variáveis com as condições ambientais. Quando se compararam os resultados da produção em laboratório com os de campo, identificou-se uma queda no desempenho mecânico do revestimento. Entretanto, como não era esse o objetivo principal deste trabalho, essa variável não foi aprofundada; porém, deverá ser objeto de pesquisas futuras, juntamente com pesquisas que considerem aspectos mais tecnológicos, tais como o consumo de material e as perdas envolvidas com essa específica técnica de aplicação de revestimentos.

\section{Referências}

AMERICAN SOCIETY FOR TESTING AND

MATERIALS. ASTM C 67: standard test methods for sampling and testing brick and structural clay tile. West Conshohocken, Pensilvânia, 2012. 12 p.

\section{ASSOCIAÇÃO BRASILEIRA DE NORMAS}

TÉCNICAS. NBR 8522: concreto: determinação do módulo estático de elasticidade à compressão. Rio de Janeiro, 1984. 16 p.

\section{ASSOCIAÇÃO BRASILEIRA DE NORMAS}

TÉCNICAS. NBR 12118: blocos vazados de concreto simples para alvenaria: métodos de ensaio. Rio de Janeiro, 2011. 13 p.

\section{ASSOCIAÇÃO BRASILEIRA DE NORMAS TÉCNICAS. NBR 13277: argamassa para} assentamento e revestimento de paredes e tetos: determinação da retenção de água. Rio de Janeiro, 2005a. 3 p.

\section{ASSOCIAÇÃO BRASILEIRA DE NORMAS}

TÉCNICAS. NBR 13278: argamassa para assentamento e revestimento de paredes e tetos: determinação da densidade de massa e do teor de ar incorporado. Rio de Janeiro, 2005b. 4 p.

\section{ASSOCIAÇÃO BRASILEIRA DE NORMAS}

TÉCNICAS. NBR 13279: argamassa para assentamento e revestimento de paredes e tetos: determinação da resistência à tração na flexão e à compressão. Rio de Janeiro, 2005c. 9 p.

\section{ASSOCIAÇÃO BRASILEIRA DE NORMAS}

TÉCNICAS. NBR 13528: revestimento de paredes e tetos de argamassas inorgânicas: determinação da resistência de aderência à tração. Rio de Janeiro, 2010. 11 p.

\section{ASSOCIAÇÃO BRASILEIRA DE NORMAS}

TÉCNICAS. NBR 13749: revestimento de paredes e tetos de argamassas inorgânicas: especificação. Rio de Janeiro, 1996. 6 p.

\section{ASSOCIAÇÃO BRASILEIRA DE NORMAS TÉCNICAS. NBR 15575-4: edifícios} habitacionais de até cinco pavimentos: desempenho: parte 4: requisitos para os sistemas de vedações verticais internas e externas. Rio de Janeiro, 2012. 51 p.

ANTUNES, R. P. N.; JOHN, V. M.

Determinação e Controle da Energia de

Impacto de Argamassas Lançadas

Manualmente. São Paulo: Epusp, 2007. 14 p.

(Boletim Técnico da Escola Politécnica da USP. Departamento de Engenharia de Construção Civil. $\mathrm{BT} / \mathrm{PCC} / 455)$. 
AUSTIN S. A.; ROBINS, P. J.; GOODIER, C. I. Construction and Repair With Wet-Process Sprayed Concrete and Mortar. Technical Report, Concrete Society, Crowthorne, UK, $\mathrm{N}^{\mathrm{0}} 56$, 44 p. 2002.

BAÍA, L. L. M; SABBATINI, F. H. Projeto e Execução de Revestimento de Argamassa. São Paulo: O Nome da Rosa, 2000. 82 p. (Coleção Primeiros Passos da Qualidade no Canteiro de Obras).

BAUER, E.; PAES, I. L. Avaliação da Movimentação e Fixação de Água em Argamassas Mistas Para Substratos Porosos, nos Momentos Iniciais (Pós-Aplicação). In: ENCONTRO NACIONAL DE TECNOLOGIA DO AMBIENTE CONSTRUÍDO, 10., São Paulo, 2004. Anais... São Paulo: ANTAC, 2004. v. 1. p. 1-12.

CANDIA, M. C.; FRANCO, L. S. Contribuição ao Estudo das Técnicas de Preparo da Base no Desempenho dos Revestimentos de Argamassa. São Paulo: Epusp, 1998. 13 p. (Boletim Técnico da Escola Politécnica da USP. Departamento de Engenharia de Construção Civil. BT/ PCC/223).

CARASEK, H. Aderência de Argamassas à Base de Cimento Portland a Substratos Porosos: avaliação dos fatores intervenientes e contribuição ao estudo do mecanismo de ligação. 285 f. São Paulo, 1996. Tese (Doutorado) - Escola Politécnica, Universidade de São Paulo, São Paulo, 1996.

CICHINELLI, G. C. Revestimento Rápido: escassez de mão de obra abre espaço para projeção mecanizada de argamassas. Revista Construção Mercado, v. 105, 2010a.

CICHINELLI, G. C. Acabamento Projetado: projeção de argamassas aumenta produtividade e qualidade dos revestimentos: conheça os principais cuidados para usá-la corretamente e alguns produtos disponíveis. Revista Téchnne, v. 158, 2010 b.

COSTA, E. B. C. et al. Avaliação do Efeito da Reologia e da Energia de Impacto na Resistência de Aderência de Revestimentos de Argamassa. In: CONGRESSO NACIONAL DE ARGAMASSAS DE CONSTRUÇÃO, 3., Lisboa, 2010. Anais... Lisboa: APFAC, 2010. v. 49.

COSTA NETO, P. L. Estatística. São Paulo: Edgard Blucher, 2002. 266 p.
CRESCÊNCIO, R M. et al. Execução de Revestimentos Com Argamassa Projetada. In: ENCONTRO NACIONAL DE TECNOLOGIA DO AMBIENTE CONSTRUÍDO, 8., Salvador, 2000. Anais... Salvador: ANTAC, 2000. v. 2, p. 1067-1074.

DUAILIBE, R. P.; CAVANI, G. R.; OLIVEIRA, M. C. B. Influência do Tipo de Projeção da Argamassa na Resistência de Aderência à Tração e Permeabilidade à Água. In: SIMPÓSIO BRASILEIRO DE TECNOLOGIA DE ARGAMASSAS, 6., Florianópolis, 2005. Anais... Florianópolis: ANTAC, 2005. p. 508-517.

FERNANDES H. C. et al. Fatores que Influenciam a Energia de Lançamento da Argamassa na Projeção Por Spray a Ar Comprimido. In: SIMPÓSIO BRASILEIRO DE TECNOLOGIA DE ARGAMASSAS, 7., Recife, 2007. Anais... Porto Alegre: ANTAC, 2007. v. 1.

FERNANDES, H. C. et al. Influência da Forma de Aplicação e da Reologia da Argamassa nas Propriedades Mecânicas dos Revestimentos. In: SIMPÓSIO BRASILEIRO DE TECNOLOGIA DE ARGAMASSAS, 8, Curitiba, 2009. Anais... Curitiba: ANTAC, 2009. v. 1.

MAIDL, B. R. Equipment for the Production of Sprayed Concrete. In: AUSTIN, S. A.; ROBINS, P. J. (Eds.). Sprayed Concrete: properties, design and application. New York: McGraw-Hill, 1995.

SABBATINI, F. H. Tecnologia de Execução de Revestimentos de Argamassa. In: SIMPÓSIO DE APLICAÇÃO DA TECNOLOGIA DO CONCRETO, 13., Campinas, SP, 1990. Anais... Campinas, 1990.

SANTOS, C. C. N. Critérios de Projetabilidade Para as Argamassas Industrializadas de Revestimento Utilizando Bomba de Argamassa Com Eixo Helicoidal. 138 f. Braslília, DF, 2003. Dissertação (Mestrado em Estruturas e Construção Civil) - Faculdade de Engenharia Civil, Universidade de Brasília, Brasília, DF, 2003.

SCARTEZINI, L. M. et al. A Influência do Preparo da Base na Aderência e na Permeabilidade à Água dos Revestimentos de Argamassa.

Ambiente Construído, Porto Alegre, v. 2, n. 2, p. 85-92, abr./jun. 2002.

SILVA, R. P. Argamassas Com Adição de Fibras de Polipropileno: estudo do comportamento reológico e mecânico. 176 f. São Paulo, 2006. Dissertação (Mestrado em Engenharia de Construção Civil e Urbana) Escola Politécnica, Universidade de São Paulo, São Paulo, 2006. 
ZANELATTO, K. C. Avaliação da Influência da

Técnica de Execução no Comportamento dos

Revestimentos de Argamassa Aplicados Com

Projeção Mecânica Contínua. 122 f. São Paulo,

2012. Dissertação (Mestrado em Engenharia Civil)

- Escola Politécnica, Universidade de São Paulo,

São Paulo, 2012.

Revista Ambiente Construído

Associação Nacional de Tecnologia do Ambiente Construído

Av. Osvaldo Aranha, $99-3^{\circ}$ andar, Centro

Porto Alegre - RS - Brasil

CEP $90035-190$

Telefone: +55 (51) 3308-4084

Fax: +55 (51) 3308-4054

www.seer.ufrgs.br/ambienteconstruido

E-mail: ambienteconstruido@ufrgs.br 